Research Article

\title{
Spatiotemporal Assessment of Temperature Data Products for the Detection of Warming Trends and Abrupt Transitions over the Largest Irrigated Area of Pakistan
}

\author{
Zain Nawaz, ${ }^{1,2}$ Xin Li, ${ }^{3,4}$ Yingying Chen $\mathbb{D}^{3,4}$ Xufeng Wang, ${ }^{1,2}$ Kun Zhang, ${ }^{3}$ Naima Nawaz, ${ }^{5}$ \\ Yanlong Guo, ${ }^{3}$ and Akynbekkyzy Meerzhan ${ }^{1,2}$ \\ ${ }^{1}$ Key Laboratory of Remote Sensing of Gansu Province, Northwest Institute of Eco-Environment and Resources, \\ Chinese Academy of Sciences, Lanzhou 730000, China \\ ${ }^{2}$ University of Chinese Academy of Sciences, Beijing 100049, China \\ ${ }^{3}$ Institute of Tibetan Plateau Research, Chinese Academy of Sciences, Beijing 100101, China \\ ${ }^{4}$ CAS Center for Excellence in Tibetan Plateau Earth Sciences, Beijing 100101, China \\ ${ }^{5}$ Department of Rural Sociology, University of Agriculture, Faisalabad 38040, Pakistan \\ Correspondence should be addressed to Yingying Chen; chenyy@itpcas.ac.cn
}

Received 27 November 2019; Revised 19 May 2020; Accepted 11 June 2020; Published 2 September 2020

Academic Editor: Nir Y. Krakauer

Copyright (C) 2020 Zain Nawaz et al. This is an open access article distributed under the Creative Commons Attribution License, which permits unrestricted use, distribution, and reproduction in any medium, provided the original work is properly cited.

\begin{abstract}
Reliable and accurate temperature data acquisition is not only important for hydroclimate research but also crucial for the management of water resources and agriculture. Gridded data products (GDPs) offer an opportunity to estimate and monitor temperature indices at a range of spatiotemporal resolutions; however, their reliability must be quantified by spatiotemporal comparison against in situ records. Here, we present spatial and temporal assessments of temperature indices $\left(T_{\max }, T_{\min }, T_{\operatorname{mean}}\right.$, and DTR) products against the reference data during the period of 1979-2015 over Punjab Province, Pakistan. This region is considered as a center for agriculture and irrigated farming. Our study is the first spatiotemporal statistical evaluation of the performance and selection of potential GDPs over the study region and is based on statistical indicators, trend detection, and abrupt change analysis. Results revealed that the CRU temperature indices ( $T_{\max }, T_{\min }, T_{\text {mean }}$, and DTR) outperformed the other GDPs as indicated by their higher CC and $R^{2}$ but lower bias and RMSE. Furthermore, trend and abrupt change analysis indicated the superior performances of the CRU $T_{\min }$ and $T_{\text {mean }}$ products. However, the $T_{\max }$ and DTR products were less accurate for detecting trends and abrupt transitions in temperature. The tested GDPs as well as the reference data series indicate significant warming during the period of 1997-2001 over the study region. Differences between GDPs revealed discrepancies of 1-2 ${ }^{\circ} \mathrm{C}$ when compared with different products within the same category and with reference data. The accuracy of all GDPs was particularly poor in the northern Punjab, where underestimates were greatest. This preliminary evaluation of the different GDPs will be useful for assessing inconsistencies and the capabilities of the products prior to their reliable utilization in hydrological and meteorological applications particularly over arid and semiarid regions.
\end{abstract}

\section{Introduction}

Future estimates of global climate patterns are directly concomitant with climate variations at regional scale [1]. The regional variation in climate parameters and assessing their statistical importance are rudimentary tools in detection of climate change [2]. The reliable climate statistics can play a dynamic role for climate change adaptation and mitigation at regional levels [3, 4]. However, the consequence of climate change is large, especially in the regions of vulnerable population [5], which leads to the reduction in agricultural productivity due to high temperature, severe drought, and flood conditions [6]. Despite the importance of other climate parameters, the long-term trend in temperature (hereafter $\left.T_{\text {mean }}\right)$ is critical for the quantification of climate changes and their possible impacts on the environment $[7,8]$. 
Therefore, understanding the spatiotemporal variation in $T_{\text {mean }}$ on regional scales is of great importance in climate monitoring and in hydroclimate studies [9]. However, the variations and increasing trend in $T_{\text {mean }}$ which eventually lead to changing climate patterns could be attributed to significant variations in specific temperature indices (hereafter $T_{\max }$, $T_{\text {min }}$, and diurnal temperature range, DTR) [10-12]. Several studies have reported the spatiotemporal variations of temperature indices and effects of climate change for different regions of the world [13-16]. These accurate and reliable air temperature records underpin our knowledge of regional and global climate changes as well as their possible impacts on water resources and agriculture $[17,18]$. The stations record may be considered as the most reliable source for retrieving meteorological data so far but, unfortunately, scarce gauge records and poor data processing quality are major obstacles in conducting such assessments [19]. Even if gauge data are available and reliable, the irregular distribution and poor spatial coverage hinder their use [20].

In recent decades, the development of temperature gridded data products (hereafter GDPs) has been proven to be reliable and cost-effective for retrieving gridded data at various scales across the globe [21]. These global temperature data products are derived from the nationwide meteorological stations located all over the world. Individual station data are geographically interpolated over onto different grid sizes using several algorithms and computational techniques, considering the physical characteristics (slope and elevation) of different regions. These multisource data products are often applied as climatological inputs for hydroclimate simulations to fill gaps in sparse observation data at regional scales [22], and the considerable increase in the use of these products is attributed to their easy accessibility, good spatiotemporal coverage, fine resolution, and continuous observations [23]. As defined by the World Meteorological Organization (WMO), at least 30 years of data are necessary for rigorous climate studies [1]. Most GDPs provide the historical records of temperature suitable for meteorological studies, whereas the records acquired from satellite products are restricted by their short duration and missing data under specific conditions such as cloud cover [24].

The evaluation of climatic GDPs has been proven to be useful for quantifying trends, variability, and various other hydroclimate applications for different regions across the globe [25]. The application of GDPs has grown rapidly with advances in their reliability, resolution, and latency. However, to date, uncertainty remains as a major concern for GDPs due to the variable spatiotemporal coverage, lack of in situ observations, relocation of gauges, and data processing practices; these constraints have required comprehensive research studies related to the assessment of GDPs at the regional scale [26]. Therefore, the reliability and accuracy of GDPs vary with time and regional climate [27], such that the assessment and evaluation of the performance and capability of the GDPs at regional scales are of great importance: in particular in the arid to semiarid regions, which are sensitive to nonsignificant variations in climate variables due to their insubstantial ecosystems [28]. Such regions are characterized by very diverse hydrological cycle that often reveals extreme behaviors, such as severe floods and prolonged droughts [29]. The predominantly arid to semiarid climate, as well as geographical location in a region of accelerated temperature rise, has placed Pakistan among the most vulnerable countries to a warming climate. Moreover, most of the local population are engaged in the agriculture sector, which is extremely vulnerable to changes in climate, yet having limited resources with which to acclimatize [30].

In recent years, few studies have reported the spatiotemporal variation in climate with limited literature focused on evaluation and assessment of global climate products with in situ records over the different regions of the country. Reference [1] reported the spatial and temporal increase in temperature indices with highest significant warming trend in $T_{\min }$ and $T_{\text {mean }}$ and insignificant $T_{\text {max }}$ variations over the different irrigation zones of Punjab Province. Similarly, [31] reported the spatial trends in temperature extremes using the Berkeley Earth Surface Temperature (BEST) data at $1^{\circ} \times 1^{\circ}$ spatial resolution over Pakistan. Furthermore, [32] assessed the accuracy assessment of different precipitation GDPs over the arid region of Pakistan. However, the aims of these studies are either focused on assessment of precipitation data products or the detection of observed trends in temperature and precipitation. Meanwhile, the spatiotemporal accuracy of GDP-derived temperature indices across the agricultural region of the country has not yet been studied. Therefore, this is the first study aiming to address this gap in knowledge by providing a detailed evaluation and assessment of the spatiotemporal uncertainties of GDPderived temperature indices in Punjab Province, Pakistan. This region is of great significance for countries' economic growth as it harvests the country's major agriculture commodities, yet the region is highly vulnerable to changes in climate pattern [1], has a high frequency of meteorological hazards, and is highly susceptible to climate change [33]. The outcomes of such studies could be useful for further improvement of temperature GDPs as well as for meteorological applications across the study region [34].

In this study, we aim to evaluate the performance of the widely used GDP temperature indices $\left(T_{\max }, T_{\min }, T_{\text {mean }}\right.$, and DTR) against reference data during the period of 1979-2015 in Punjab Province. We also focus on the evaluation and comparison of temporal changes in trends and abrupt changes of GDPs. The GDPs assessed here are the Global Historical Climatology Network-Monthly (GHCN), Center for Climatic Research-University of Delaware (UDEL), Asian Precipitation Highly Resolved Observational Data Integration towards Evaluation (APHRODITE), Climate Prediction Centre (CPC), University of Princeton, Global meteorological Forcing dataset (PGF), and Climatic Research Unit (CRU). We consider the usefulness of this study as multidirectional because our findings could be used as a reference for the selection of potential GDPs in many different hydroclimate studies across Punjab Province.

\section{Materials and Methods}

2.1. Site Description. Pakistan is located in SW Asia. The country has an area of $8 \times 10^{6} \mathrm{~km}^{2}$, including diverse 
landscapes ranging from the Karakoram and Himalayan mountains in the north and northwest to the agricultural plains of the Indus River basin in the center and the Arabian Sea along the southern coast [35]. Punjab Province is Pakistan's second largest province, with geographical coordinates of $31.17^{\circ} \mathrm{N}$ and $72.70^{\circ} \mathrm{E}$ (Figure 1). Additionally, the province has the largest population and is the agricultural hub of the country, producing more than $50 \%$ of the country's agricultural commodities [36]. The province includes five major rivers, namely, the Jhelum, Chenab, Ravi, Bias, and Sutlej. There are seven irrigation zones in Punjab (Thal, Sargodha, Lahore, Multan, Faisalabad, Dera Ghazi (D.G.) Khan, and Bahawalpur). The annual mean precipitation ranges from $>800 \mathrm{~mm}$ in the northern part to $<300 \mathrm{~mm}$ in the southern part [37]. There are two precipitation seasons in this region: the monsoon season (July-September) and winter (December-March) [38]. The annual mean temperature varies from 23 to $26^{\circ} \mathrm{C}$, with $T_{\min }$ of $16-19^{\circ} \mathrm{C}$ and $T_{\max }$ of $29-33^{\circ} \mathrm{C}$. Overall, the northern part of the region is dominated by humid and subhumid climates, while the central and southern parts are dominated by tropical and coastal climates.

\subsection{Stations Data and Processing. Historical variations in} annual air temperature indices ( $T_{\max }, T_{\min }, T_{\text {mean }}$, and DTR) were investigated as reference data for the evaluation of GDPs over the study region. Long-term records of temperature indices from 1979 to 2015 from 20 meteorological gauges in Punjab were provided by the Pakistan Meteorological Department (PMD) (Figure 1). These gauges were selected on the basis of their maximum available time coverage, uniformity, and completeness of the series records. The in situ records and GDPs were investigated and evaluated on an annual scale. GDPs were developed using quality-controlled stations data. Therefore quality-controlled reference data were required for the evaluation of selected GDPs. The annual gauge and GDP data series were annual means of monthly averages. The quality control of the gauge records (such as detection of outliers and procedure for missing gaps) is of primary importance. For quality assurance, outliers were fixed with neighboring gauge records and gaps were obtained from nearby gauges [39]. Missing values in the records were filled by interpolation technique using a time-based approach: e.g., the mean value of that month over a period of \pm 2 years surrounding the missing value [40].

Numerous methods have been used to detect the outliers and inhomogeneities in the gauge records [41]. Here, the double-mass curve method was applied to the stations records [42]. The adjustment and detection of inconsistencies in station records was achieved by concomitant its variability with other relatively stable records [43]. Nonlinearity or bends can indicate relocation of the gauges or installation of a new instrument [44]. The result of the double-mass curve indicated a straight line, with no evident break points, which confirms a high temporal uniformity in the station records. After performing standard quality control checks, the spatial interpolation thin-plate smoothing splines (ANUSPLIN) method was used to convert the gauge data onto grids of 0.5 degree resolution for spatial evaluation of the GDPs. The original thin-plate spline fitting technique is described by [45], while [46] provides a theoretical description of its application to surface climate variables. The spline interpolation method is robust in areas where there are irregularly spaced gauges and a prior estimation of the spatial autocovariance structure is not required [46].

The degree or significance of autocorrelation was checked in the observed data series of air temperature indices by using time series autocorrelation technique prior to detecting the trends significance, trend magnitude, and abrupt transition over time by using Mann-Kendall (MK), Sen's slope, and Sequential Mann-Kendall (SQMK) methods [1]. The possibility of identifying a significant trend increases with the escalation in autocorrelation, which would influence the outcomes of the trend tests [47]. Consequently, the occurrence of autocorrelation should be checked prior to applying the MK tests [48]. Our analysis found no significant autocorrelation in annual time series of $T_{\text {max }}, T_{\text {min }}, T_{\text {mean }}$, and DTR at lag-1. Therefore, the station records are independent and the trend test is applicable to the original station records. The detailed procedure for autocorrelation analysis is reported in [49].

2.3. Gridded Data Products (GDPs). In this study, six temperature index data products (GHCN, UDEL, APHRODITE, CPC, CRU, and PGF) were evaluated against the reference data (Table 1). Details of the datasets are described as follows.

2.3.1. CRU. The Climate Research Unit (CRU) TS V4 product was developed by the University of East Anglia, UK, and is continuously updated with the support from National Centre for Atmospheric Science (NCAS) and Natural Environment Research Council (NERC), UK. The product comprises several climate variables including temperature indices $\left(T_{\max }, T_{\text {min }}, T_{\text {mean }}\right.$, and DTR), precipitation, cloud cover, vapor pressure, wet-day counts, potential evapotranspiration, and wet-day frequency. The product is prevalent because of its relatively long history (1901-present) and its horizontal spatial resolution of 0.5 degrees. The product has been developed from more than 11,800 meteorological stations around the world [50]. The main sources used for construction of monthly datasets were acquired from the national meteorological agencies (NMAs), the World Meteorological Organization (WMO), National Climatic Data Center, NCDC, USA, University of East Anglia CRU, the Food and Agriculture Organization (FAO), Centro Internacional de Agricultura Tropical, and others. In this study, we used monthly datasets of temperature indices ( $T_{\max }, T_{\text {min }}, T_{\text {mean }}$, and DTR) for the period of $1979-2015$ at 0.5 -degree resolution.

2.3.2. UDEL. The UDEL V5.01 product was developed by the University of Delaware, USA. The primary data of air surface temperature and precipitation were acquired from various sources including Global Historical Climatology Network (GHCN2, daily GHCN) at the National Centers for 


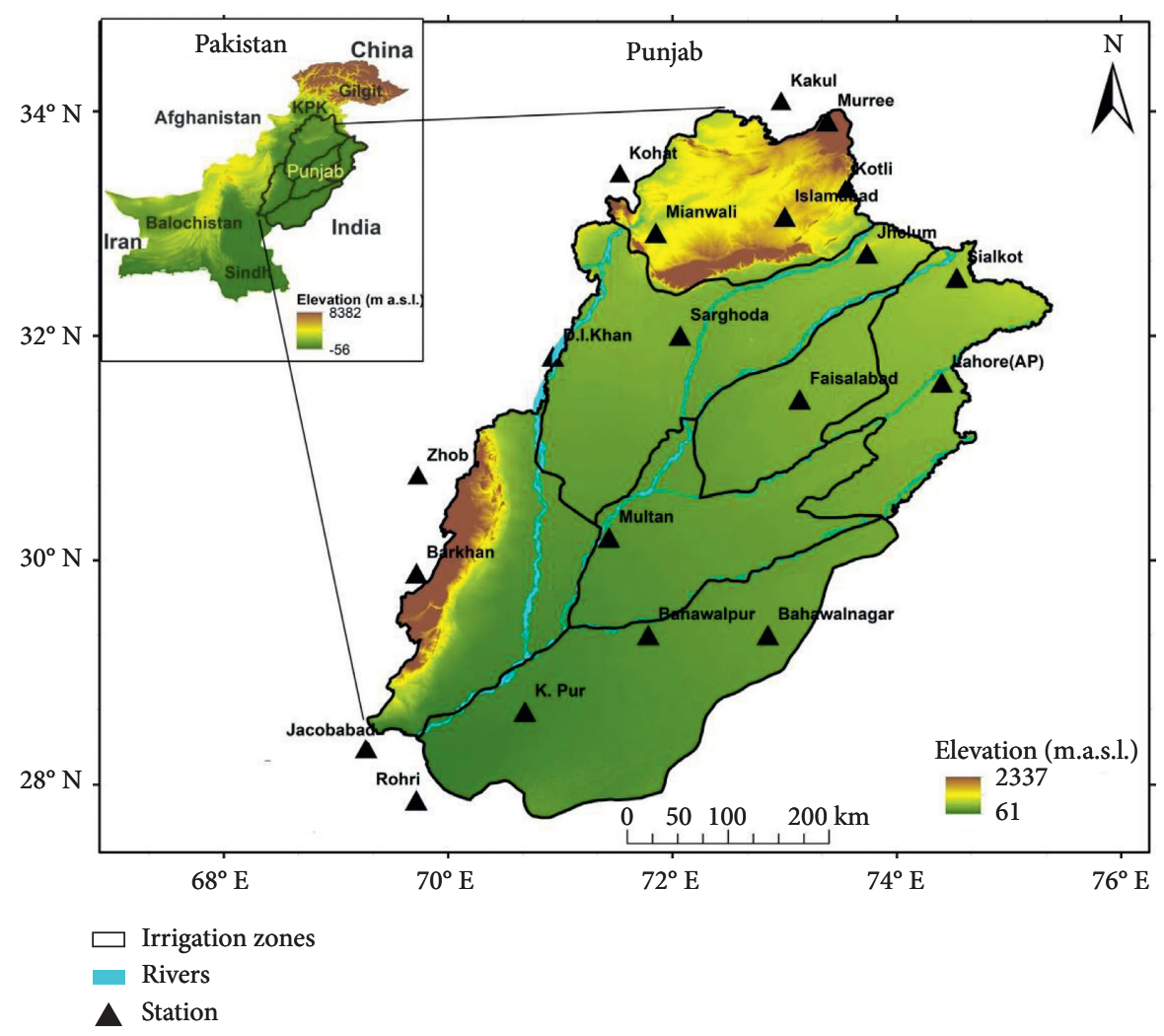

Figure 1: Location of the study area and its climatic stations.

TABLE 1: Information on global gridded products used in the study.

\begin{tabular}{lccccc}
\hline Datasets & Variable & Resolution & Frequency & $\begin{array}{c}\text { Study temporal } \\
\text { coverage }\end{array}$ & Source \\
\hline APHRODITE & $T_{\operatorname{mean}}$ & $0.5^{\circ} \times 0.5^{\circ}$ & Monthly & $1979-2015$ & High Asian Product, Japan \\
\hline CRU & $\begin{array}{c}T_{\operatorname{mean}}, T_{\max } \\
T_{\min }, \text { DTR }\end{array}$ & $0.5^{\circ} \times 0.5^{\circ}$ & Monthly & $1979-2015$ & University of East Anglia \\
\hline CPC & $\begin{array}{c}T_{\text {mean }}, T_{\max }, \\
T_{\min }\end{array}$ & $0.5^{\circ} \times 0.5^{\circ}$ & Monthly & $1979-2015$ & Climate Prediction Center \\
\hline UDEL & $T_{\operatorname{mean}}$ & $0.5^{\circ} \times 0.5^{\circ}$ & Monthly & $1979-2015$ & [46] \\
\hline GHCN & $T_{\operatorname{mean}}$ & $0.5^{\circ} \times 0.5^{\circ}$ & Monthly & $1979-2015$ & [47] \\
\hline PGF & $T_{\max }, T_{\min }$ & $0.5^{\circ} \times 0.5^{\circ}$ & Monthly & $1979-2015$ & $\begin{array}{c}\text { Princeton University Global Meteorological } \\
\text { Forcing (NCEP-ncar) Reanalysis Dataset }\end{array}$ \\
\hline
\end{tabular}

Environmental Information, Atmospheric Environment Services Canada, Institute of Hydrometeorology in St. Petersburg, daily records from Greenland Climate Network data, daily records from the Global Surface Summary of the Day, the National Center for Atmospheric Research (NCAR) India, and Nicholson's precipitation data archive of Africa, station records from South America, and monthly records from the Automatic Weather Station Project Greenland [51]. The product provides monthly values for the period of 1900-2017 at 0.5-degree spatial resolution. In this study, we used monthly datasets of $T_{\text {mean }}$ for the period of 1979-2015 at 0.5 -degree resolution.

2.3.3. $C P C$. The CPC gauge-based product is the first product covering both land and ocean data from the CPC Unified Precipitation Project at the National Oceanic and
Atmospheric Administration (NOAA). The CPC acquired data and constructed various climate parameters on daily and monthly scales; these include precipitation, temperature, snow cover, and degree-days. The product collected data reports from 30,000 stations, including reports from the Global System of Telecommunication (GTS) data, Cooperative Observer Network (COOP), and other national meteorological agencies (NMAs) [52]. The CPC product database covers the period from 1979 till the present at 0.5degree spatial resolution. In this study, we used monthly datasets of temperature indices $\left(T_{\max }, T_{\min }\right.$, and $\left.T_{\text {mean }}\right)$ for the period of 1979-2015 at 0.5-degree resolution.

2.3.4. APHRODITE. Asian Precipitation-Highly Resolved Observational Data Integration towards Evaluation of Water Resources (APHRODITE) products V1808 and V1101 of 
daily surface air temperature and precipitation were developed by the Meteorological Research Institute of the Meteorological Agency and Japan Institute for Humanity and Nature. The gauge dataset is first interpolated at 0.05degree resolution. Further datasets are generated after regridding to 0.25 - and 0.5 -degree resolution by considering the local attributes, with the aid of improved algorithms for the weighting function [53]. The product provides daily values for the period of 1961-2015. The primary datasets were acquired from national meteorological agencies (NMAs), Global Telecommunication System (GTS) data, International Center for Integrated Mountain Development (ICIMOD), International Water Management Institute (IWMI), and other international projects on Asian climate. In this study, we used the monthly datasets of $T_{\text {mean }}$ for the period of 1979-2015 at 0.5-degree resolution.

2.3.5. GHCN. The Global Historical Climatological Network-monthly (GHCN) data product V3 was developed by the National Climatic Data Center (NCDC) and National Centers for Environmental Information. It provides the temperature monthly mean data for 7280 stations in 226 countries [54]. The product covers the period from the early 1900 s to present, with horizontal spatial resolutions of 5 and 0.5 degrees. The primary datasets are acquired from national meteorological agencies (NMAs), Global Telecommunication System (GTS) data, the National Center for Atmospheric Research (NCAR), World Weather Records, and other data sources. In this study, we used the monthly $T_{\text {mean }}$ product at 0.5-degree resolution from 1979 to 2015.

2.3.6. PGF. The product was developed by assimilating the National Centers for Environmental Prediction-National Center for Atmospheric Research (NCEP-NCAR) reanalysis datasets with several global observed databases [55]. The product comprises different climate variables, including air temperature indices $\left(T_{\max }\right.$ and $\left.T_{\min }\right)$, precipitation, downward short and longwave radiation, surface pressure, specific humidity, and wind speed. The product is available at 3hourly, daily, and monthly resolution from 1949 to the present with horizontal spatial resolutions of 1 and 0.5 degrees. In this study, we used the monthly datasets of $T_{\max }$ and $T_{\min }$ for the period of 1979-2015 at 0.5-degree resolution.

\subsection{Descriptive Methods}

2.4.1. Statistical Evaluation. In the present study, the spatiotemporal performance of each GDP was assessed against reference or gauge data by using significant statistical indicators. Several quantitative evaluation metrics, including the Pearson correlation coefficient (CC), root mean square error (RMSE), and standard deviation, were applied using a Taylor diagram, which is an accurate method of quantifying the degree of agreement between GDPs and reference data [56]. Moreover, the coefficient of determination ( $R$-squared) was also used for each GDP against the reference data to quantify their respective linear relationships between the gauge and GDPs. The percentage bias (rBias) was then calculated to indicate the level of over- or underestimation of GDPs against observation data on a spatiotemporal scale. The equations for these statistical metrics are as follows:

$$
\begin{aligned}
\mathrm{CC} & =\frac{\sum_{i=1}^{n}\left(G_{i}-\bar{G}\right)\left(P_{i}-\bar{P}\right)}{\sum_{i=1}^{n}\left(G_{i}-\bar{G}\right)^{2} \times \sqrt{\sum_{i=1}^{n}\left(P_{i}-\bar{P}\right)^{2}}} \\
\mathrm{rBias} & =\frac{\sum_{i=1}^{n}\left(G_{i}-P_{i}\right)}{\sum_{i=1}^{n} G_{i}} \times 100, \\
\mathrm{RMSE} & =\sqrt{\frac{1}{n} \sum_{i=1}^{n}\left(P_{i}-G\right)^{2},} \\
R^{2} & =\left(\frac{\sum_{i=1}^{n}\left(G_{i}-\overline{\bar{G}}\right)\left(P_{i}-\overline{\bar{P}}\right)}{\sqrt{\sum_{i=1}^{n}\left(G_{i}-\bar{G}\right)^{2} \sum_{i=1}^{n}\left(P_{i}-\bar{P}\right)^{2}}}\right)^{2},
\end{aligned}
$$

where $G_{i}$ and $\bar{G}$ refer to the gauge data and mean of gauge data or observation data, $P_{i}$ and $\bar{P}$ refer to the gridded products and mean of gridded products, respectively, and $n$ is the total number of observations. According to [57], the statistical estimates are considered appropriate if their values satisfy CC $>0.7$, RMSE and $R$-squared near 0 , and rBias in the range of -10 to $10 \%$. Positive values of rBias indicate underestimation of temperature by the GDP and vice versa for negative values [58].

2.4.2. Mann-Kendall (MK) Test. The nonparametric MK trend analysis was used to evaluate the GDPs against reference data series. The MK test is robust against missing values and outliers [52] and is less sensitive to the abrupt disruption points and inhomogeneous data series [43]. The test has been widely used for the detection of hydrological and meteorological variations and trends in sequential data series $[59,60]$. The governing equations for statistics $(S)$, variance Vas $(S)$, and standardized $(Z)$ statistics of MK test for identical and independent distributed datasets are as follows:

$$
\begin{aligned}
S & =\sum_{p=1}^{n-1} \sum_{j=p+1}^{n} \operatorname{sgn}\left(x_{j}-x_{p}\right), \\
\operatorname{sgn}\left(x_{j}-x_{p}\right) & = \begin{cases}1, & \text { if } x_{j}>x_{p} \\
0, & \text { if } x_{j}=x_{p}, \\
-1, & \text { if } x_{j}<x_{p}\end{cases} \\
\operatorname{Vas}(S) & =n(n-1)(2 n+5)-\sum_{h=1}^{m} t_{h}\left(t_{h}-1\right) \frac{\left(2 t_{h}+5\right)}{18}, \\
Z & = \begin{cases}\frac{(S-1)}{\sqrt{\operatorname{VAR}(S)}}, & S>0 \\
0, & S=0 . \\
\frac{(S+1)}{\sqrt{\operatorname{VAR}(S)}}, & S<0\end{cases}
\end{aligned}
$$


In these equations, $n$ and $x_{p}, x_{j}$ are defined as the series length and data sequential values, respectively. $t_{h}$ is the size of the $p t_{h}$ tied group and $m$ is the number of tied groups. The standardized $(Z)$ statistics follow the symmetric distribution with a null hypothesis $\left(H_{0}\right)$ of no trend in the data series [61]. However, the alternative hypothesis was that there has been a significant trend in the time series data [62]. The negative and positive values of the $(Z)$ statistics represent decreasing and increasing trends, respectively.

2.4.3. Theil and Sen's Slope (TSS). The nonparametric TSS technique is used to quantify the magnitude of slope in linear trends [63] and is widely acceptable and used for the investigation of hydrological and meteorological data series [64]. The TSS employs regression method and is broadly used for estimating the rate of slope magnitude in linear trends of temporal data series [65]. The TSS computed slope magnitude is not affected by the inconsistencies in the temporal data series [30]. The basic equation for the computation of trends magnitude is defined as follows:

$$
S_{i}=\frac{x_{j}-x_{p}}{J-p} \quad \text { if } J>p \text { For } i=1, \ldots, N,
$$

where $N$ is the length of temporal data series and $x_{j}$ and $x_{p}$ are the data values at times $j$ and $p$, respectively. Furthermore, the TSS equations for the even and odd length of temporal data series are as follows:

$$
Q_{\mathrm{med}}= \begin{cases}Q_{((n+1) / 2)}, & \text { if } N \text { is an even number, } \\ \frac{1}{2}\left[Q_{(N / 2)}+Q_{((N+2) / 2)}\right], & \text { if } N \text { is an odd number. }\end{cases}
$$

2.4.4. Sequential Mann-Kendall (SQMK). The SQMK trend test is used to detect significant positive or negative turning point in a time series data [48]. The trend test sets up two data series, that is, retrograde series (RS) and progressive series (PS). The statistics value of progressive series is the same as $(Z)$ statistics, which ranges from initial to end data point. Conversely, the retrograde series is estimated backward and originates from end to initial data point in a temporal data series. If the two data series cross each other and attain explicit threshold values at a certain point, then there is significant positive or negative trend. The abrupt turning point shows the beginning of statistically significant trend in a time series [43]. The increasing and decreasing abrupt changes in PS and RS data series indicate positive and negative trends, respectively [66]. The following procedure is adopted for the estimation of abrupt changes in a given time series. The SQMK test statistics $\left(T_{j}\right)$ are defined as follows:

$$
T_{j}=\sum_{p}^{j} n_{j}
$$

where ' $n_{j}$ ' is computed by comparing the magnitude of annual averages of sequential time series $x_{j}(j=1, \ldots, n)$ with $x_{p}(p=1, \ldots, j)$, as well as number of times $x_{j}>x_{p}$ are counted. The mean $(E)$ and variance (Var) of $T_{j}$ are computed by

$$
\begin{aligned}
E(T) & =\frac{[n(n-1)]}{4}, \\
\operatorname{Var}\left(T_{j}\right) & =\frac{j(j-1)(2 j+5)}{72} .
\end{aligned}
$$

Subsequently, the test statistics, PS and RS, are calculated by the following equation:

$$
\operatorname{PS}(T)=\frac{\left[T_{j}-E(T)\right]}{\sqrt{\operatorname{var}}\left(T_{j}\right)} .
$$

Similarly, RS $(T)$ is estimated starting from end to initial data point. The hypothesis $H_{0}$ in the test would be accepted at a corresponding level of significance, if $\mathrm{PS}(T) \leq \mathrm{PS}(T)$ ${ }_{1-\alpha / 2}$, where PS $(T)_{1-\alpha / 2}$ is the captious value of a symmetric distribution with a value of probability above $\alpha / 2$. The level of $\alpha$ is set at 0.05 in the study. The abrupt point is contemplated to be significant at $95 \%$ confidence level (i.e., \pm 1.96 ).

\section{Results}

3.1. Temporal and Spatial Dynamics. The annual averages and temporal variability of temperature indices $\left(T_{\max }, T_{\min }\right.$, $T_{\text {mean }}$, and DTR) as estimated from reference and GDPs over Punjab are shown in Figures 2 and 3. The results indicated that all the GDPs of temperature indices overestimated the temperature when compared with the reference data. However, the degree of overestimation varied by $1-2^{\circ} \mathrm{C}$ between different products. The most representative temporal trends in the temperature indices were found in the CRU, PGF, and UDEL products. All other products also demonstrated their ability to capture the temporal variability over the study region but with notable overestimation. Overall, the performance of the CRU products was better in terms of temporal variability and magnitude. Figure 4 illustrates the spatial distribution pattern of GDPs and reference data. The spatial pattern of gauge-based temperature indices indicated a higher to lower south-north temperature gradient in Punjab, with magnitudes of $34.02-22.5^{\circ} \mathrm{C}$, $19.03-11.45^{\circ} \mathrm{C}, 15.84-11.28^{\circ} \mathrm{C}$, and $28.48-14.53^{\circ} \mathrm{C}$, respectively. The GDPs exhibited similar patterns to those of the reference data with notable overestimation in all the products. The spatial pattern was best matched by the $T_{\text {mean }}$ products. Overall, the most accurate spatial patterns were achieved by the CRU, UDEL, and PGF products, while the lowest accuracies were achieved by the CPC product for temperature extremes $\left(T_{\max }\right.$ and $\left.T_{\min }\right)$ and GHCNM $T_{\text {mean }}$ when compared with reference data over the study region.

The performances of GDPs relative to the reference data were further evaluated based on statistical metrics as presented in Table 2. The results again indicate that all the products overestimated temperature, with notable values of rBias in the CPC and GHCNM products. However, CRU products $T_{\max }, T_{\min }, \mathrm{DTR}$, and $T_{\text {mean }}$ performed better in 


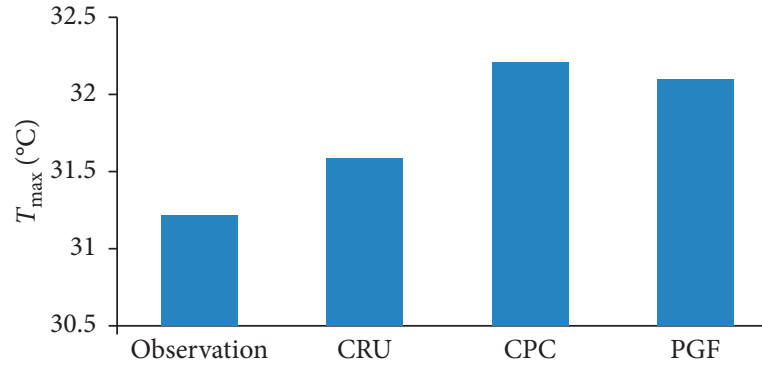

(a)

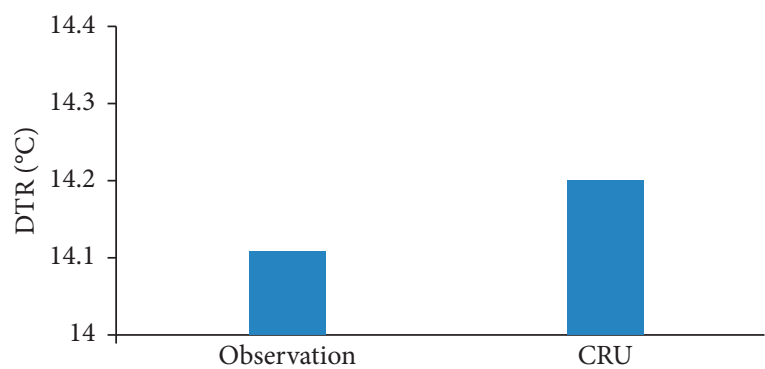

(c)

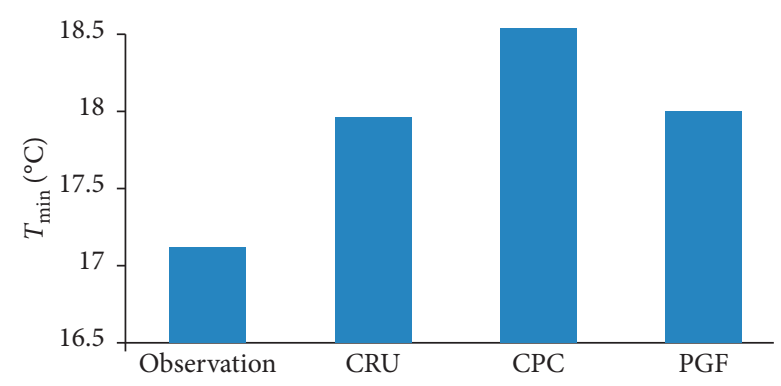

(b)

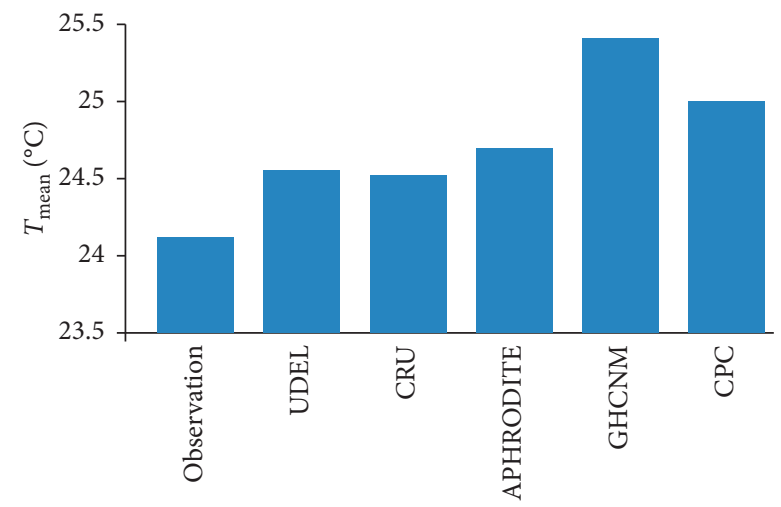

(d)

Figure 2: Average annual (a) $T_{\max }$, (b) $T_{\min }$, (c) DTR, and (d) $T_{\text {mean }}$ of observation data and GDPs.

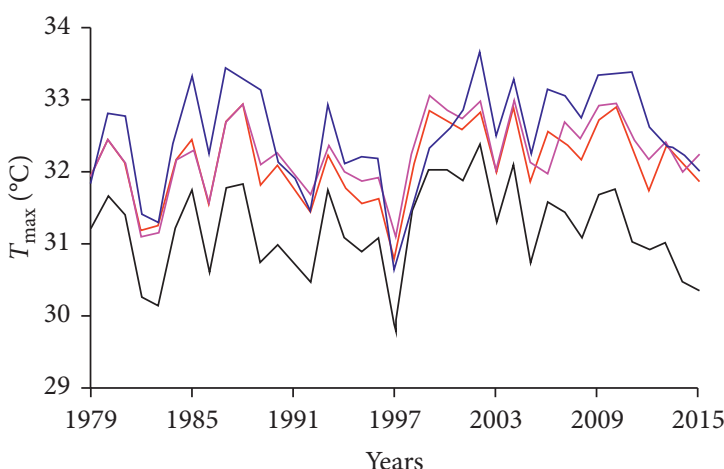

- Obs
CRU

- $\mathrm{CPC}$

(a)

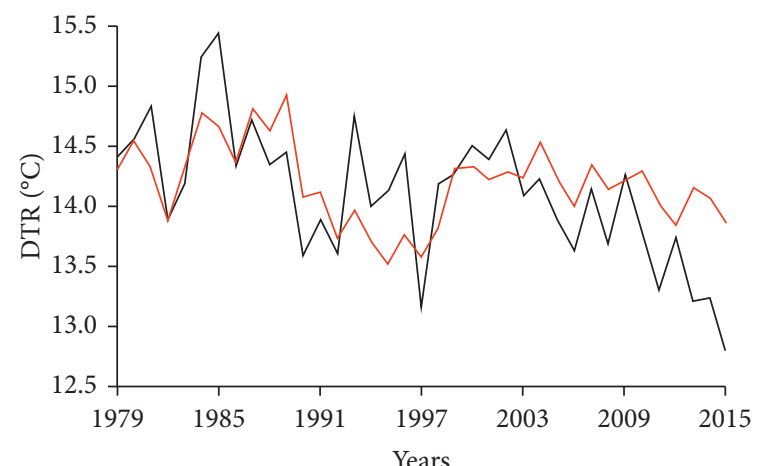

- Obs
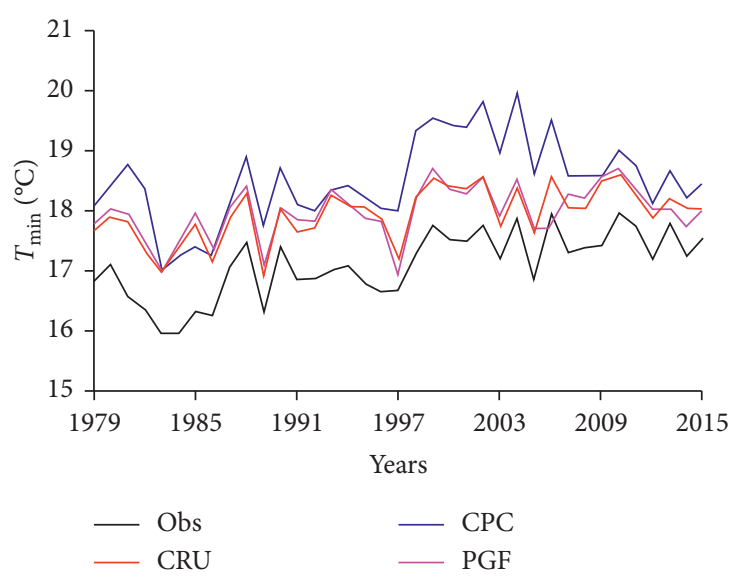

(b)

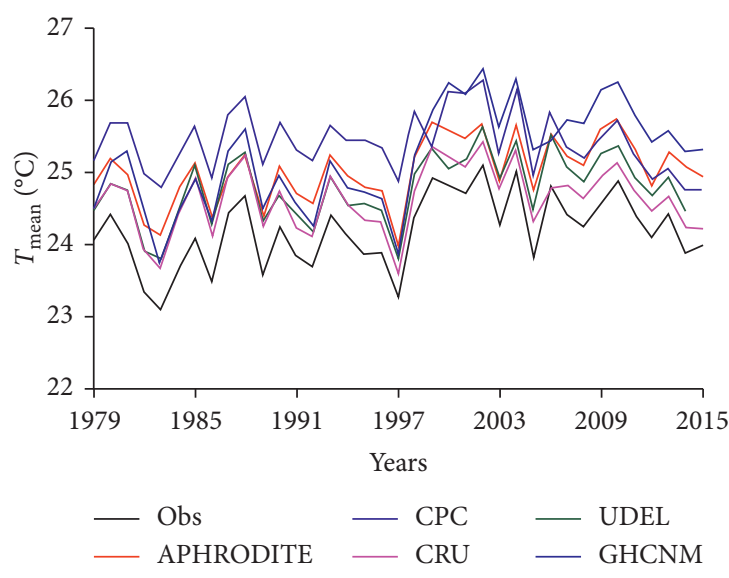

(d)

FIGURE 3: Temporal comparison of observation data and GDPs for (a) $T_{\max }$ (b) $T_{\min }$, (c) DTR, and (d) $T_{\text {mean }}$. 

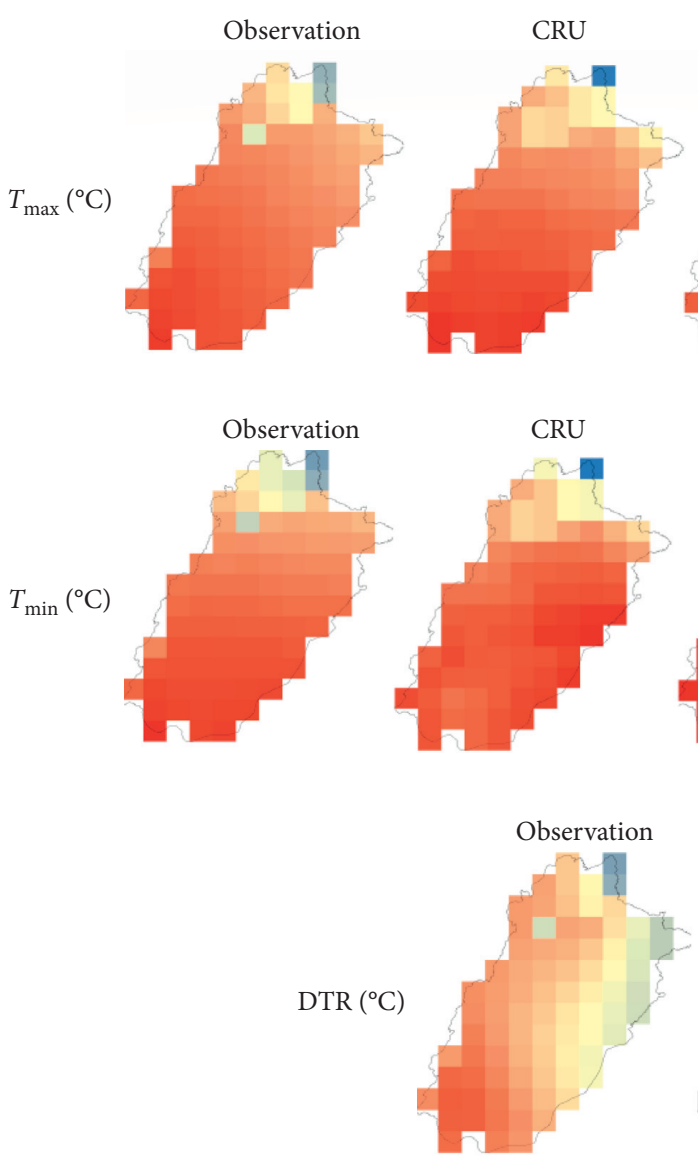
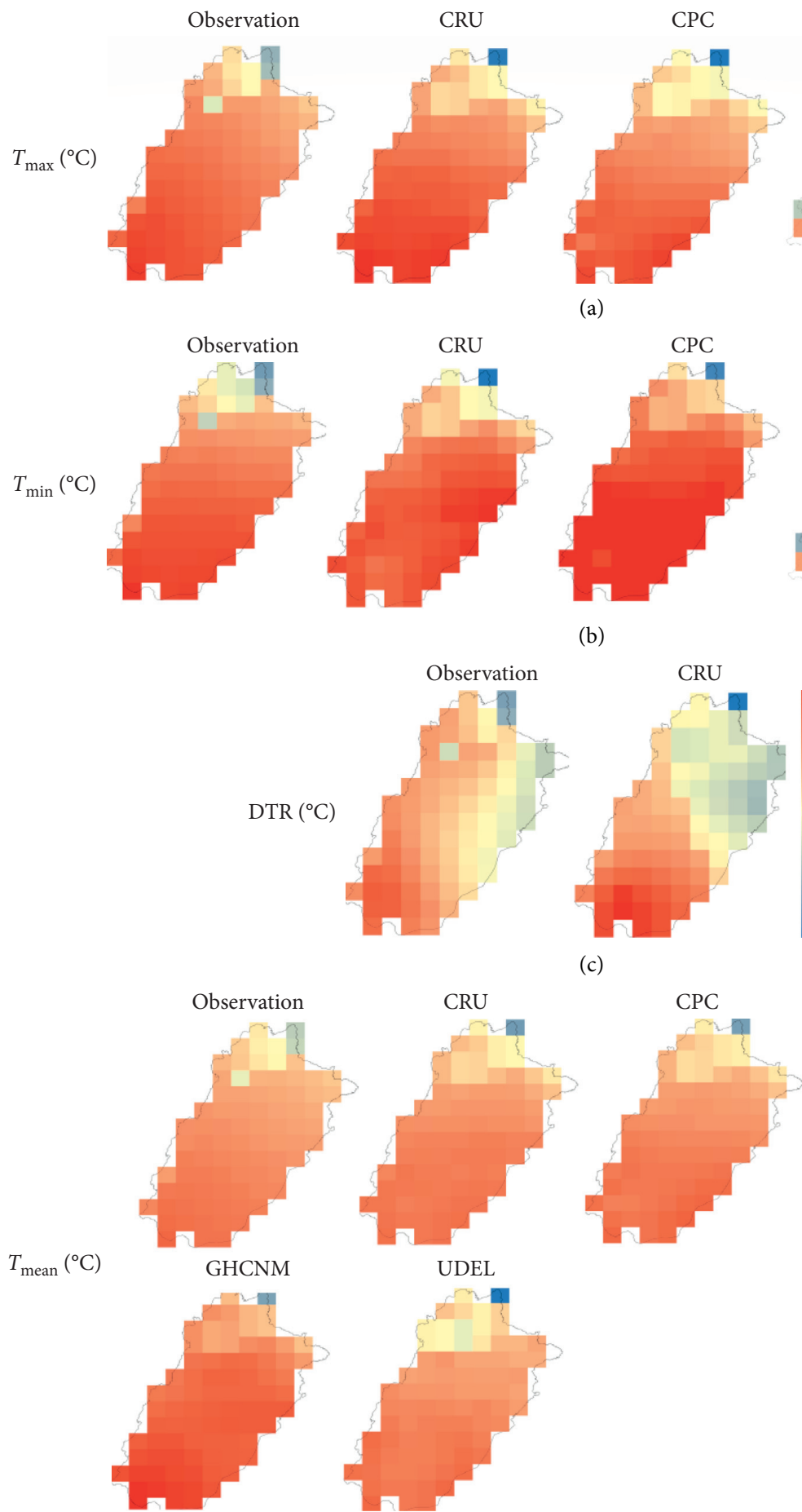

(a)

(b)

(c)
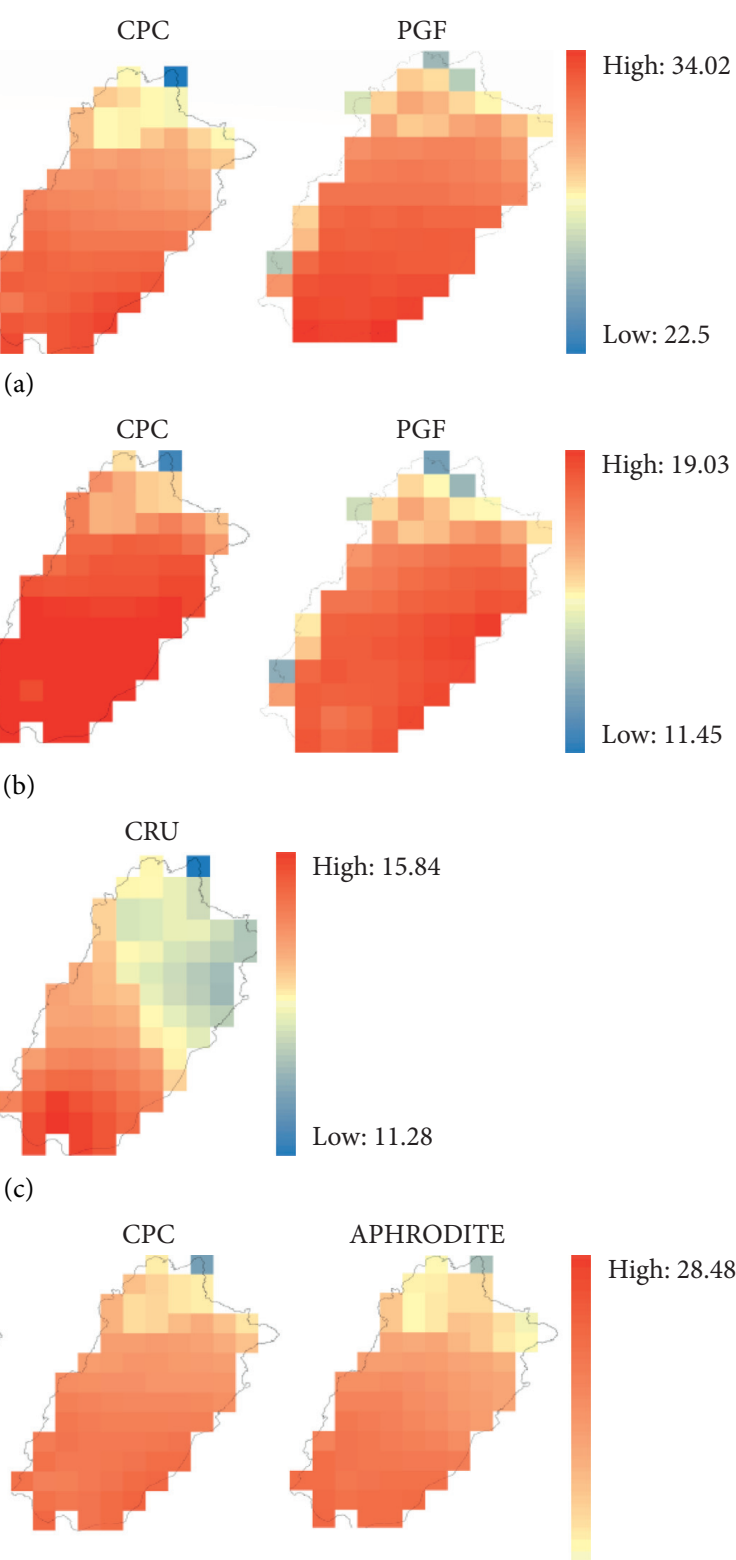

Low: 14.53

(d)

FIgURE 4: Spatial distributions of average annual temperature indices over Punjab. (a) $T_{\max }$, (b) $T_{\min }$, (c) DTR, and (d) $T_{\text {mean }}$.

terms of their higher values of CC $(0.90,0.89,0.63$, and 0.97$)$ and $R^{2}(0.79,0.80,0.63$, and 0.93$)$ but lower values of rBias $(-2.3,-0.49,-0.60$, and -1.5$)$ and $\operatorname{RMSE}(0.28,0.26,0.44$, and 0.13 ). The performance of other GDPs also showed moderate agreements but with higher error metrics when compared with reference data. To further compare the different GDPs against reference data, Taylor diagram was plotted [56], which quantifies agreement between the reference and GDPs in terms of their correlation coefficients (CC), standard deviation (SD), and root mean square error (RMSE), as shown in Figures 5(a)-5(d). The Taylor diagram illustrates the pattern and degree of similarity of GDPs and shows how far away the GDPs plot is from the reference data [67]. In the diagram, CC is shown by blue lines perpendicular to the parabolic scale; SD is shown by radii of the black circles and RMSE is shown by radii of the green circles. 
TABLE 2: Statistical metrics for the evaluation of temperature indices GDPs.

\begin{tabular}{|c|c|c|c|c|}
\hline Indices & RMSE & $\mathrm{CC}$ & $R^{2}$ & rBias (\%) \\
\hline \multicolumn{5}{|l|}{$\left(T_{\min }\right)$} \\
\hline CRU & 0.18 & 0.93 & 0.80 & -0.49 \\
\hline СРC & 0.44 & 0.80 & 0.65 & -7.2 \\
\hline PGF & 0.20 & 0.90 & 0.71 & -5.1 \\
\hline \multicolumn{5}{|l|}{$\left(T_{\max }\right)$} \\
\hline CRU & 0.28 & 0.90 & 0.79 & -2.3 \\
\hline $\mathrm{CPC}$ & 0.39 & 0.83 & 0.69 & -6.8 \\
\hline PGF & 0.32 & 0.85 & 0.72 & -3.3 \\
\hline \multicolumn{5}{|l|}{ (DTR) } \\
\hline $\mathrm{CRU}$ & 0.44 & 0.63 & 0.45 & -0.6 \\
\hline \multicolumn{5}{|l|}{$\left(T_{\text {mean }}\right)$} \\
\hline APHRODITE & 0.22 & 0.90 & 0.87 & -3.1 \\
\hline CRU & 0.13 & 0.97 & 0.93 & -1.5 \\
\hline GHCNM & 0.19 & 0.93 & 0.90 & -2.7 \\
\hline UDEL & 0.15 & 0.95 & 0.91 & -1.84 \\
\hline $\mathrm{CPC}$ & 0.20 & 0.94 & 0.88 & -3.4 \\
\hline
\end{tabular}

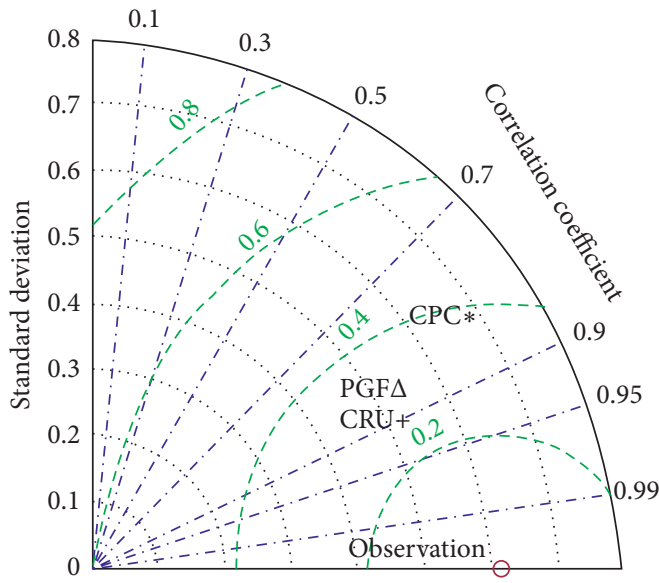

(a)

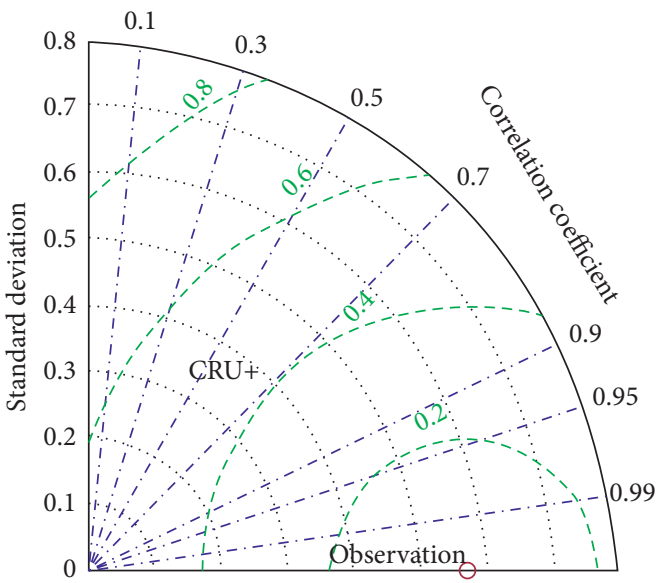

(c)

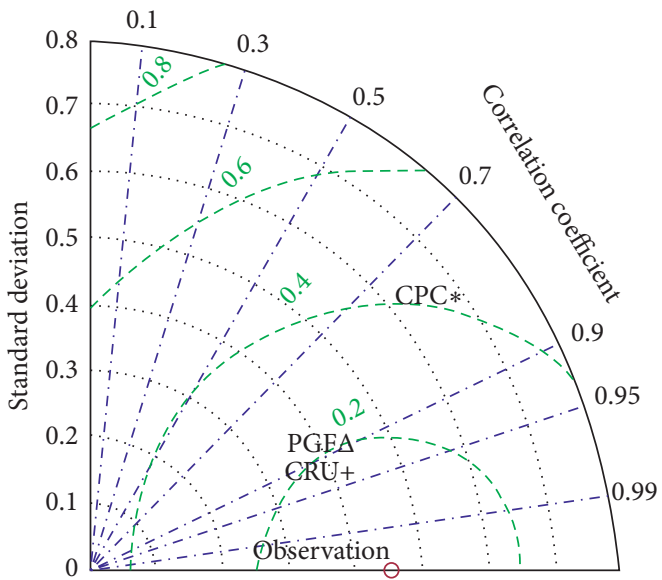

(b)

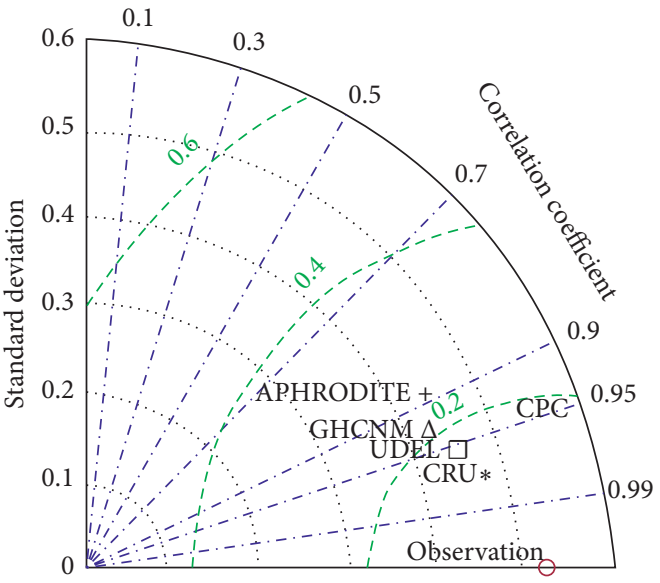

(d)

Figure 5: Statistical comparison of observation data and GDPs for (a) $T_{\max }$, (b) $T_{\min }$, (c) DTR, and (d) $T_{\text {mean }}$.

The results indicate that the CRU GDP outperformed the other products, as indicated by the points plotting closer to the reference data while also having higher CC and lower RMSE values. The PGF and UDEL products also showed reasonable agreement with the reference data. Meanwhile, the CPC and DTR of CRU products showed relatively poor performance when reproducing the patterns in the reference data. 
The spatial distributions of Bias, RMSE, and CC used to evaluate $T_{\max }, T_{\min }, \mathrm{DTR}$, and $T_{\text {mean }}$ of the GDPs against the reference data over the Punjab region during the whole research period are shown in Figure 6. The statistical metrics highlight discrepancies in the spatial patterns of GDPs against the reference data [67]. The spatial metrics indicate that the estimation of CRU, UDEL, and PGF $T_{\text {min }}$ products achieved the best agreements when compared with reference data. The relative GDPs of $T_{\max }, T_{\text {min }}, T_{\text {mean }}$, and DTR showed poor performances as indicated by the magnitudes of Bias, RMSE, and CC. Furthermore, intercomparison of the temperature indices demonstrates similar spatial patterns among the CRU, UDEL, APHRODITE, PGF, and CPC $T_{\text {mean }}$ products. However, the CPC $T_{\text {min }}$ and GHCNM $T_{\text {mean }}$ products yielded patterns that were the inverse of relative products with large overestimations.

Meanwhile, the CPC temperature indices were the least accurate among all the products when capturing the spatial distribution pattern. Most products showed similar patterns, with positive Bias in the northern part of the study region, indicating that temperatures were underestimated in the high altitude of northern Punjab. The temperature index products were less able to capture the spatial distribution pattern, particularly in northern Punjab. This could be attributed to topographic effects and the relatively coarse spatial resolution of GDPs when attempting to capture variability in high altitude areas. Overall, the range of statistical parameters in these areas demonstrates the importance of the bias correction of GDPs before their use in climate studies [67]. Overall, the CRU products showed the most consistent spatial pattern and best agreement with the reference data, particularly in central Punjab, with comparatively higher values of CC and lower values of Bias and RMSE.

3.1.1. Trend Detection. The annual trends of GDPs and reference data series acquired by the MK and TSS approaches at $95 \%$ confidence interval (CI) during the study period of 1979-2015 are presented in Figures 7(a)-7(d), showing that the $T_{\max }$ and $T_{\min }$ GDPs overestimated and underestimated the trends when compared with their respective reference data series, respectively. $T_{\max }$ from the CRU, PGF, and CPC products overestimated the insignificant trend magnitude by rates of $0.13,0.15$, and $0.15^{\circ} \mathrm{C}$.decade $\mathrm{e}^{-1}$, respectively. However, the reference $T_{\max }$ showed an insignificant increasing trend of $0.03^{\circ} \mathrm{C}$.decade ${ }^{-1}$. The observed trend in $T_{\max }$ is consistent with the previous findings [1], where an insignificant positive trend was observed with a magnitude of $0.01^{\circ} \mathrm{C}$. decade $^{-1}$ during the period of 1967-2017. In the case of $T_{\min }$, the reference data showed a significant positive trend with a rate of $0.31^{\circ} \mathrm{C}$. decade $^{-1}$, while CRU, PGF, and CPC products underestimated the significant increasing trend and yielded magnitudes of $0.23,0.13$, and $0.21^{\circ} \mathrm{C}$.decade ${ }^{-1}$, respectively. Similarly, the reference DTR indicated a significant negative trend with a rate of $-0.32^{\circ} \mathrm{C}$.decade ${ }^{-1}$, whereas the CRU product underestimated the insignificant negative trend with a slope rate of $-0.11^{\circ} \mathrm{C}$. decade ${ }^{-1}$. The study outcomes indicated that the slope magnitude of reference $T_{\min }$ increased at a faster rate than $T_{\max }$, which resulted in higher rate of decrease in DTR. The conspicuous escalation in $T_{\min }$ trends over the study region were well captured by the respective GDPs. The present results are well concurred with the findings of $[31,68]$, which reported the faster rate of increase in $T_{\min }$ than that of $T_{\max }$ data series. However, the corresponding slope magnitude is different, which could be the result of different region, time period, and computational algorithms of GDPs.

Furthermore, the APHRODITE, CRU, GHCNM, UDEL, and CPC $T_{\text {mean }}$ products indicated positive trends with magnitudes of $0.16,0.19,0.14,0.07$, and $0.17^{\circ} \mathrm{C}$. decade $^{-1}$, respectively. The slopes of the APHRODITE, CRU, and CPC products revealed significant trends at $95 \% \mathrm{CI}$, while insignificant increasing trends were observed in the GHCNM and UDEL products. The highest and lowest accuracies to detect the trends magnitude were observed in CRU and UDEL products as compared with reference $T_{\text {mean }}$ data series. The comparative results of CRU $T_{\min }$ and $T_{\text {mean }}$ products showed the best performance against reference data for capturing the significance and magnitude of trends. However, the GDPs for $T_{\max }, T_{\min }$, and DTR were comparatively less accurate when assessing the significance and magnitudes of respective trends over the study region. Overall, the reference and GDPs $T_{\min }$ and $T_{\text {mean }}$ data series indicated the significant warming over the study region. However, the trends in $T_{\max }$ showed insignificant changes during the study period. Almost all $T_{\max }$ GDPs overestimated the magnitude as compared with reference data. Consequently, the $T_{\max }$ products were less capable of detecting the trends significance and slope magnitude over the study region.

3.1.2. Abrupt Changes. Abrupt changes in climate data series reveal the transition from one climate state to another, due to some external factors, at a rate determined by the climate system $[69,70]$. The Sequential Mann-Kendall (SQMK) test was applied to detect changes in the temperature index trends when evaluating and comparing the different GDPs with reference data series during the period of 1979-2015 over the Punjab region. The retrograde and progressive trend series were attained at the 0.05 significance level. The results of annual transition plots of $T_{\max }$, $T_{\text {min }}$, DTR, and $T_{\text {mean }}$ GDPs and the reference data series are shown in Figures 8(a)-8(d). Figure 8(a) for $T_{\max }$ of the GDPs (CRU, CPC, and PGF) shows similar trends in the progressive series when compared with the reference data. The reference series showed five transition points during the whole study period. However, all the $T_{\max }$ products failed to capture the exact transition points in the $T_{\max }$ data series.

The results of abrupt transition in the $T_{\min }$ GDPs and reference data series are shown in Figure 8(b) and indicate that the CRU outperformed the other products when compared with the reference data. The CRU and reference data both showed similar patterns of gentle upward drive 


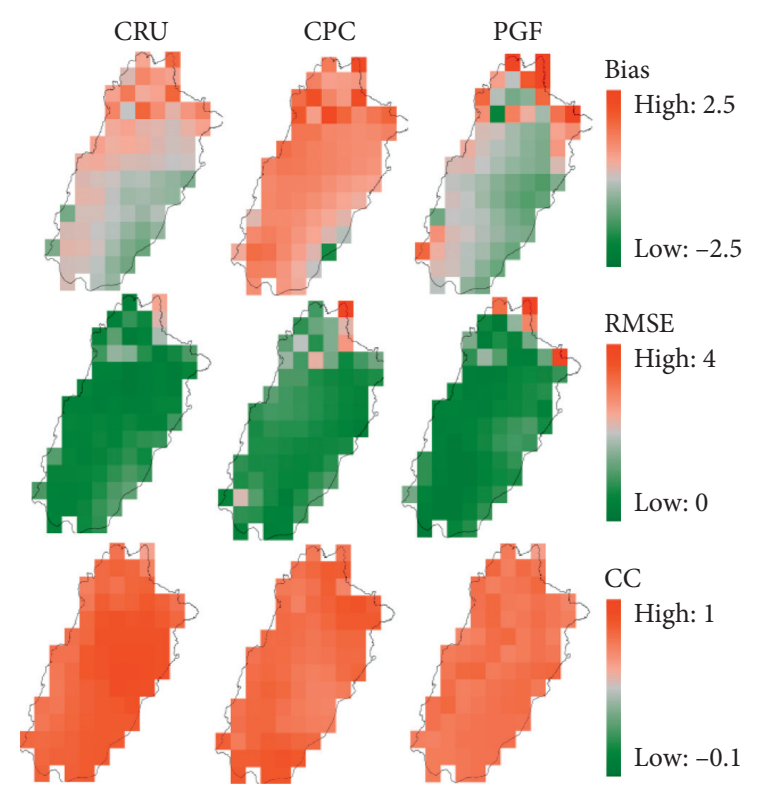

(a)

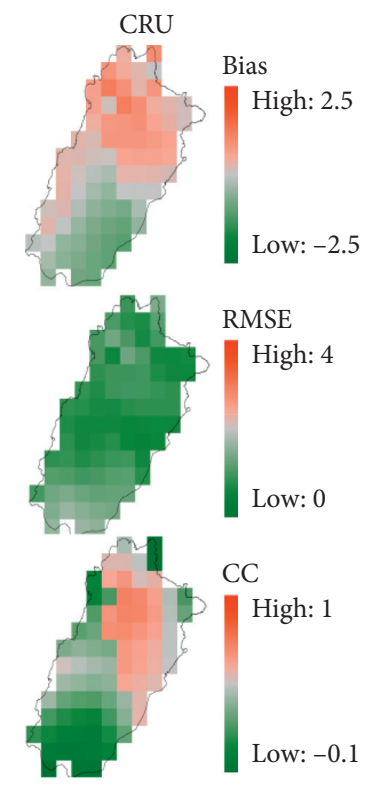

(c)

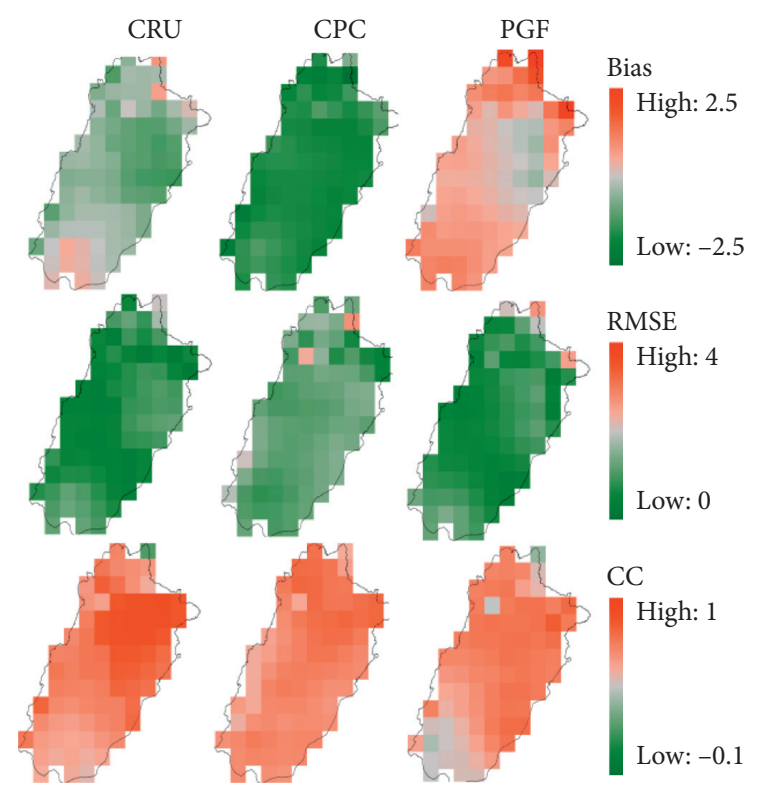

(b)
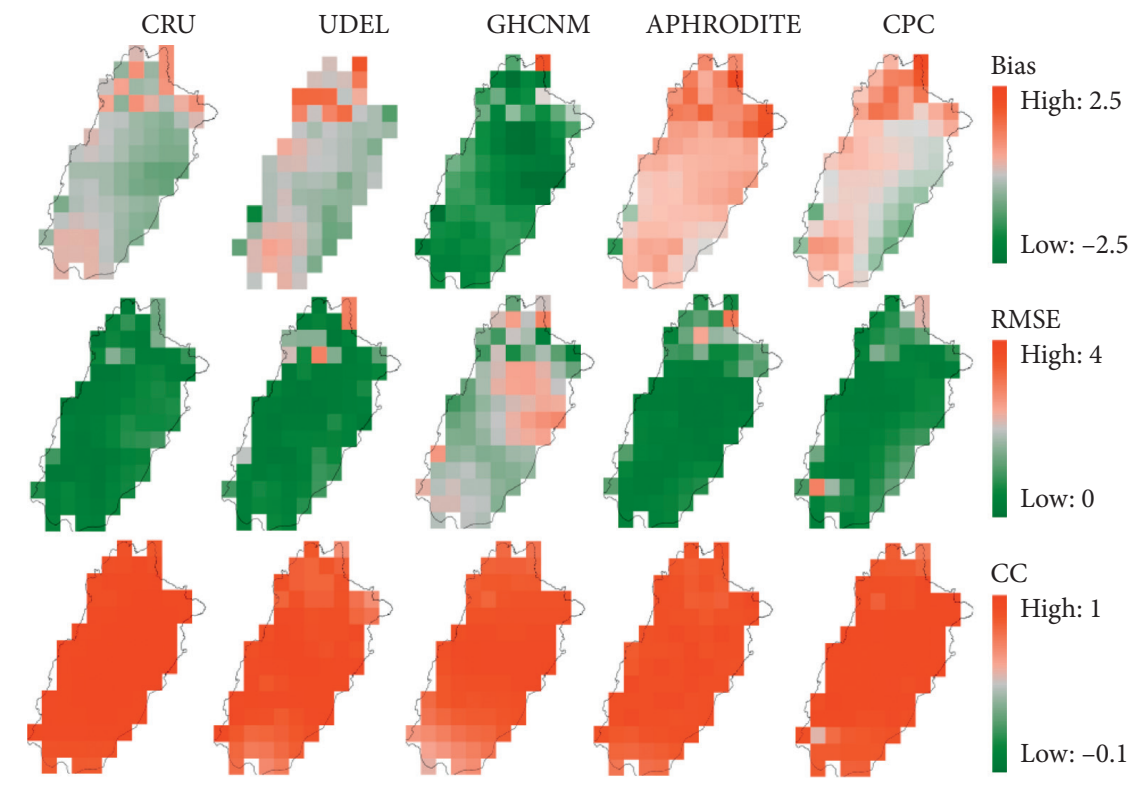

(d)

Figure 6: Spatial distribution of Bias, RMSE, and CC of temperature indices when comparing GDPs against observations for (a) $T_{\text {max }}$, (b) $T_{\min },(\mathrm{c}) \mathrm{DTR}$, and (d) $T_{\text {mean }}$.

during the period of 1984. However, the CPC and PGF products were found to be relatively less accurate at detecting transitions in the temperature trend. The transition results of the DTR product and reference data series during the period of 1967-2017 are shown in Figure 8(c), indicating similar patterns with negative shifts in both the CRU and reference DTR series. However, the negative shift was stronger in the reference data series when compared with the CRU product. Moreover, no mutation point was detected in CRU and reference data series throughout the study period.

The detection of rapid change points and comparison of $T_{\text {mean }}$ in the GDPs (APHRODITE, GHCNM, UDEL, CRU, and $\mathrm{CPC}$ ) with those of the reference data are shown in Figure 8(d). The results show that the CRU and GHCNM products outperformed the other GDPs at capturing the abrupt transition points (negative during 1997-98 and positive during 2000-01) when compared with reference data. All the other GDPs also showed a reasonable ability to detect the patterns in progressive and retrograde series. However, the transition points of the APHRODITE, UDEL, and CPC $T_{\text {mean }}$ products were different from those of the reference data series. Overall, the CRU and GHCNM $T_{\text {mean }}$ products showed the best performance in detecting abrupt changes in temperature, when compared with the reference data series. The positive shift in temperature during 


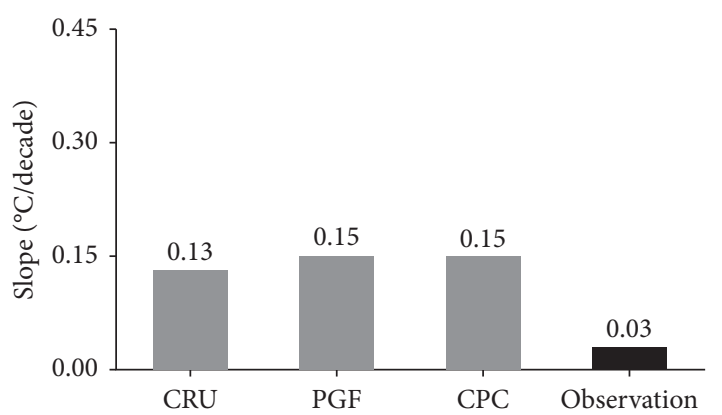

(a)

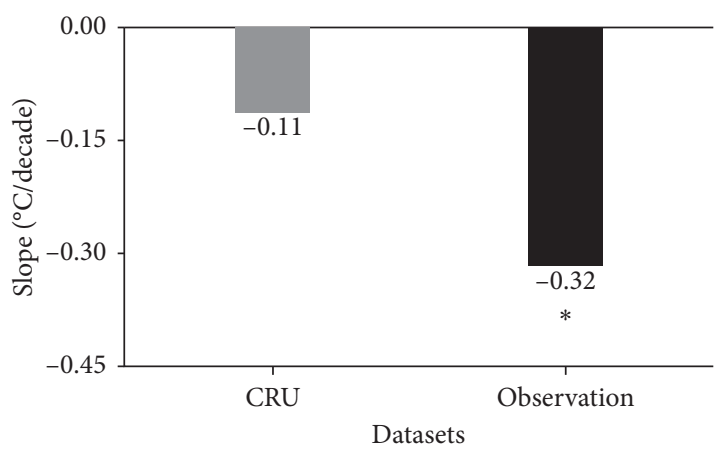

(c)

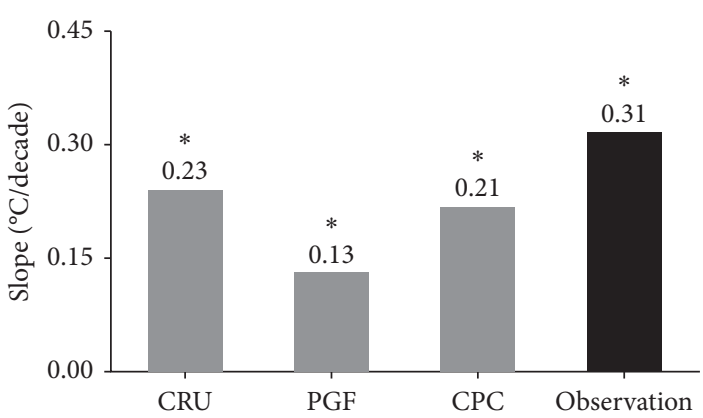

(b)

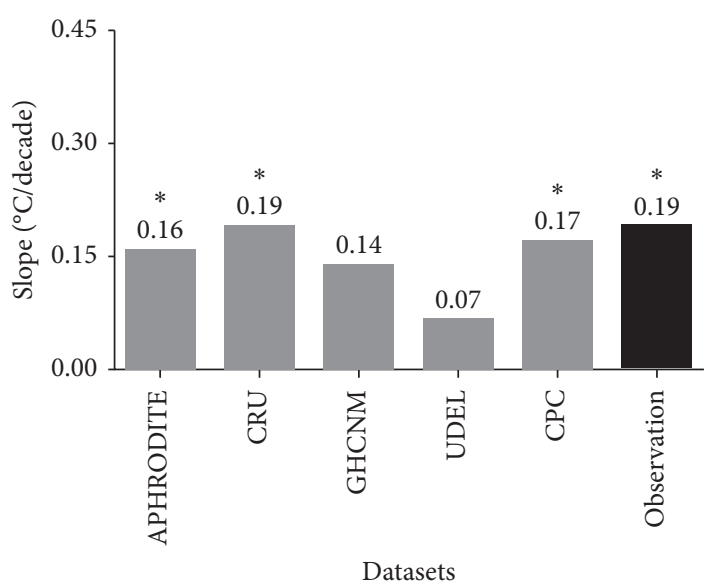

(d)

Figure 7: Comparison of MK trend slopes ( ${ }^{*}$ significant trend at 95\% CI) of the observation data and GDPs for (a) $T_{\max }$, (b) $T_{\min }$, (c) DTR, and (d) $T_{\text {mean }}$.

1979-2001 revealed that study region experienced a relatively hot period during this time. The results agree well with previous studies that have found hot, dry periods over several parts of Pakistan [71, 72]. The transitions in temperature during this period were better captured by the CRU and GHCNM products than by the other GDPs.

\section{Discussion}

Accurate and reliable spatiotemporal temperature data acquisition is not only important for studies of climate variations but also crucial for the water resources and agriculture management [73]. The present study used in situ records to evaluate global temperature indices $\left(T_{\max }, T_{\min }, T_{\text {mean }}\right.$, and DTR) available as GDPs during the period of 1979-2015 in Punjab Province, Pakistan, by using several spatial and temporal statistical metrics (including trend and abrupt change analyses). The in situ records selected for the evaluation may also be subject to physical and nonphysical changes, and efforts were made to reduce their effects. Similarly, GDPs were selected for the evaluation as they are widely used, have longer time series, and are available at higher spatial resolution. The length of the in situ records and the spatial and temporal scales of the GDPs satisfy the conditions required for evaluation of climate forcing data for hydrological modelling at the regional level as prescribed by the WMO [74].
Results showed that the spatial and temporal performances of the CRU temperature indices outperformed the other GDPs as indicated by their high values of CC and $R^{2}$ but lower values of rBias and RMSE. Furthermore, the significance and abrupt transitions in temperature trends of the reference data series were well captured by the CRU $T_{\min }$ and $T_{\text {mean }}$ products. However, the $T_{\max }$ and DTR products were less able to detect the respective trends and abrupt changes. This is the first attempt to evaluate the performance of temperature GDPs over the Punjab region; therefore, the outcomes of this study could be used as a reference point for future studies with similar scope. The results of our investigation were found to be consistent with equivalent findings in other countries and with some previous studies of temperature variability over different parts of the country. The present findings of the superior performance of CRU products were well concurred with the findings of [31], which reported the promising results of CRU product against reference data in terms of higher correlation and lower bias over the Italy. Similarly, the current results are well associated with the findings of [75] that reported the moderate accuracy of CRU air temperature products against the station records by using Taylor statistic approach over the Canadian arctic during the period of 1950-2010. On the contrary, [76] reported the satisfactory behavior of GHCN and UDEL air temperature products by using different statistical metrics over the southwestern region of Brazil. 

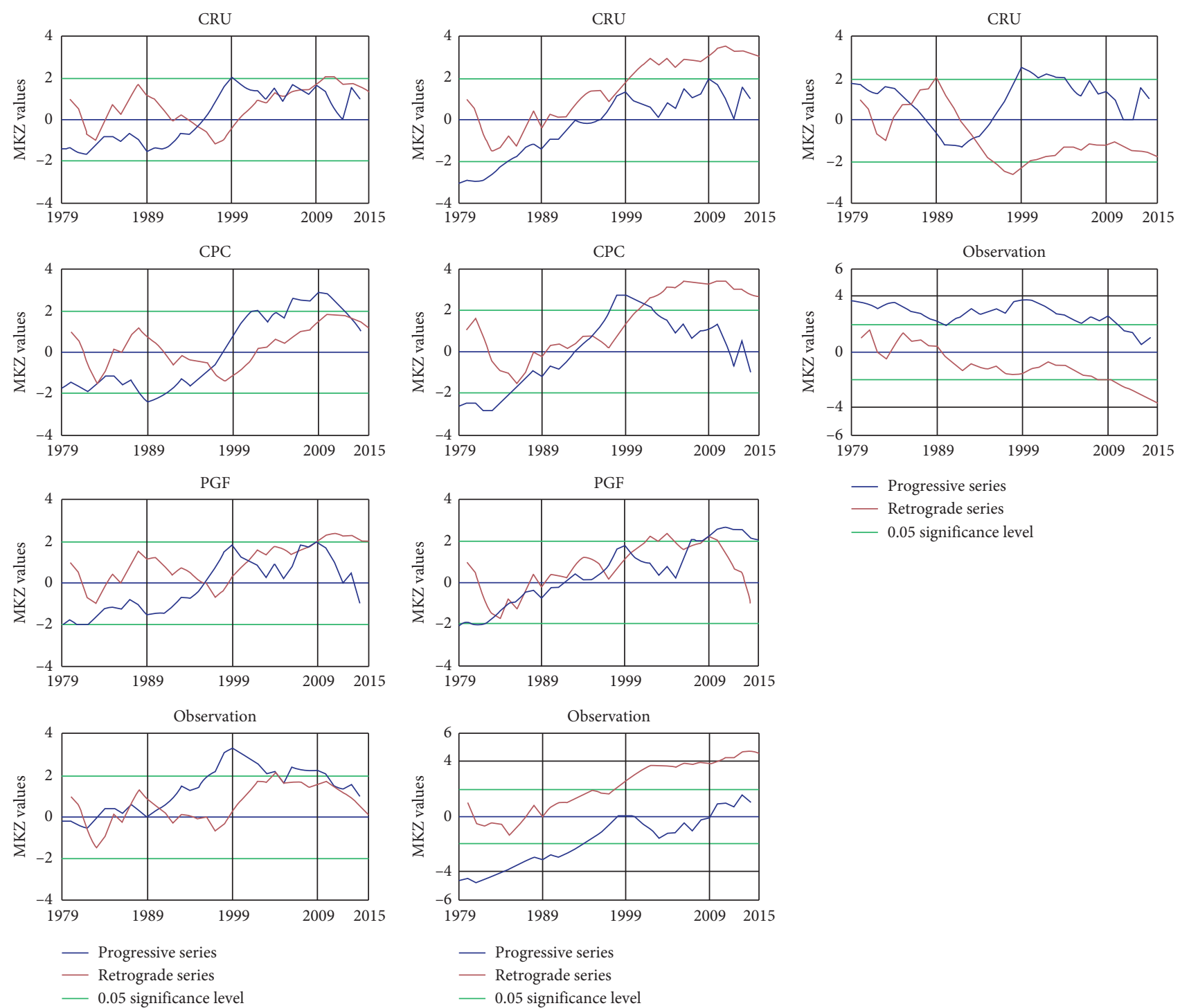

\section{- Progressive series \\ _ Retrograde series \\ - 0.05 significance level}

(a) (b)

(c)

Figure 8: Continued. 

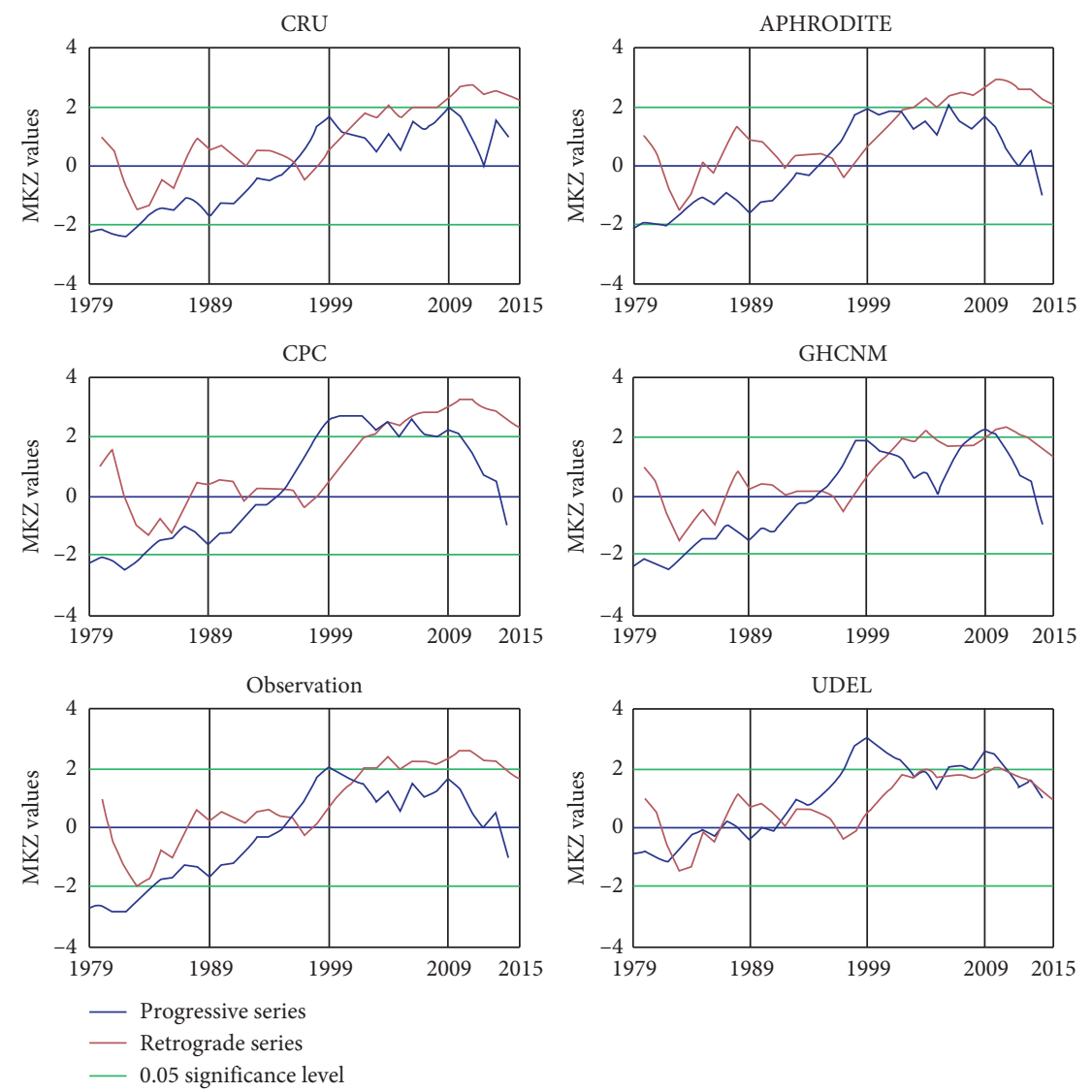

(d)

FIgURE 8: Comparison of abrupt transitions in observation data and GDPs for (a) $T_{\max }$, (b) $T_{\min }$, (c) DTR, and (d) $T_{\text {mean }}$.

Moreover, the findings of $[77,78]$ revealed the better performance of APHRODITE and UDEL air temperature GDPs in India and Middle East-North Africa region in terms of higher agreement in correlation, $R^{2}$ value, and NSE range between -0.5 and 0.5 , respectively. The variation in GDPs performances pointed out the importance of global products evaluation at regional level as it fluctuates with time and region by using different statistical metrics [74].

Furthermore, the current results indicated significant warming trends during the period of 1979-2015 over the study region, which could be attributed to rapid urbanization, deforestation, or population growth across the study region [79]. According to [36], the population of the study region has been expanded exponentially in recent years, which may affect the long-term trends in temperature. The current findings showed significant positive trends in $T_{\min }$ with a faster rate than $T_{\max }$, which is consistent with the findings of [31], which reported the significant increase in $T_{\min }$ compared to $T_{\max }$ by using gridded Berkeley Earth Surface Temperature (BEST) data of spatial resolution of $1^{\circ} \times 1^{\circ}$ over the whole country. Similarly, the significant warming and conspicuous increase in $T_{\min }$ data series were also reported by [43] for Iran and $[48,68]$ for Italy and India, respectively. However, the difference in magnitude could be associated with the different study period, stations, and region. Moreover, the abrupt change results showed an abrupt transition of temperature in the reference data series during the period of 1997-2001. Several studies have reported severe droughts and hot conditions in the country during this period [80-82]. The significant warming during this period, which could be related to the extreme droughts and hot conditions over the study region, was well captured by the CRU GDPs. However, the $T_{\max }$ GDPs were less accurate to detect the rate of change and abrupt transition over the study region.

Overall, we found considerable spread in the magnitude and temporal variability among the different GDPs over the study region, with differences reaching $1-2^{\circ} \mathrm{C}$ between different products within the same category as well as between GDPs and the reference data. The range of uncertainties was more notable in the extreme temperature $\left(T_{\max }\right.$ and $\left.T_{\min }\right)$ products than in the $T_{\text {mean }}$ products. Furthermore, the spatial variability and range of uncertainty in the GDPs over northern Punjab were more prominent than those over central and southern Punjab. However, most of the GDPs underestimated the temperature indices in most of their pixels across northern Punjab. This may have been due to interannual weather variability, fewer gauges, or orographic effects in the northern part of the province. Several studies have documented such effects in climate studies of the northern belt of Pakistan [67, 83]. Central and southern Punjab was covered by a relatively smaller number of pixels 
and showed a weaker ability of GDPs to capture the spatial variability, perhaps due to urbanization in these areas. Most of the gauge networks are installed in nonurban domains, which could impact the estimation accuracy in urban areas. Several studies related to climate variability have indicated that urbanization affects the spatial variability in climate [84].

The spatial and temporal performances of the datasets depend on a number of factors related to the processing of the GDPs, for example, data sources, interpolation techniques, temporal domain, missing data, topography, and spatial resolution [85]. Similarly, the quality, number of stations, and time scale of the reference data used for the comparison of global GDPs are also very important for the identification of potential climate GDPs in specific regions [32]. The detection of autocorrelation in the datasets is another important test to ensure the accuracy of trend detection and abrupt change analyses in the climate data series. However, the presence of autocorrelation was more significant for precipitation products, particularly for highaltitude regions above $4000 \mathrm{~m}$ [67]. The superior performance of the CRU temperature index $\left(T_{\max }, T_{\min }, T_{\text {mean }}\right.$, and DTR) GDPs over the Punjab region might be due to their better data processing procedures, higher number of gauge stations, and superior interpolation techniques. The CRU product acquired data from 11,800 stations worldwide, covering relatively long historical records and higher spatial resolution (1901-present). The quality of the CRU data is checked through a two-stage process for better consistency and reliability; for more details, see [50, 86]. The GDPs used different numbers of stations in different years when calculating the spatial gridded data [32], so it is difficult to estimate the number of stations used by GDPs each year over the study region. The GDPs, even with their intrinsic biases and limitations, are still an important source of information related to climate variability on various spatial and temporal scales. The global GDPs are also important for climate studies when there is a lack of funding or resources available for collecting field observations. Caution must be exercised when comparing and using the GDPs, since there may be large uncertainties where gauge density is low [87].

Our study summarizes and compares some potential GDPs for temperature indices over Punjab Province. The evaluation results can improve our understanding of the use of GDPs in arid and semiarid regions like Punjab Province. Meanwhile, spatial and temporal discrepancies were also identified, which will be useful in the further application of these GDPs in hydrometeorological applications. The reference data were used as a standard for the assessment of different global products. However, different systematic errors related to the reference data compromise the quality of evaluation process. Thus, the regions with less number of meteorological stations available with sufficient geographic distribution and the use of global products could be proved satisfactory [76]. Considering the significant biases in all six GDPs tested in the study region, we recommend establishing a correction factor for each dataset before use in further climate studies in the region. Further steps should also be considered, for example, the selection of station networks and homogenization to remove urbanization affects while constructing the GDPs in populated countries such as Pakistan. Moreover, higher-quality reference data should be considered once more accurate gauge data and a denser network are available for the evaluation of spatiotemporal GDPs over Punjab Province.

\section{Conclusion}

Through comparison with reference data, this study highlights the spatial and temporal strengths and weaknesses of different temperature GDPs; this will help in the selection of potential GDPs for Punjab Province, Pakistan. Notable differences and similarities in the bias, trends, and abrupt transition in temperature were identified for these different GDPs over the target region. The core findings of the study are listed below.

The spatial and temporal performances of the CRU product were better than those of the other GDPs in terms of the higher values of CC and $R^{2}$ but lower values of Bias and RMSE. Furthermore, the trends and abrupt change analyses (using MK and SQMK tests) indicate the superior performance of the CRU $T_{\min }$ and $T_{\text {mean }}$ products in terms of the trend significance, similar spatial patterns, and similar transition points when compared with reference data series during the whole study period and over the entire study region. However, the $T_{\max }$ and DTR products were less able to detect the respective trends and abrupt changes. Transition points in the GDP and reference data series indicated significant warming during the period of 1997-2001, which could be the outcome of drought and hot condition in the country during this period [72]. Moreover, GDPs and reference data series revealed a significant change in $T_{\min }$ as compared to $T_{\max }$ and, as a consequence, higher reduction in DTR over the study region. The present findings are broadly consistent with the studies conducted at local, regional, and neighboring countries [31, 43, 77]. However, the rate of change and trends magnitude of GDPs data series are different from each other due to different data sources and computational algorithms. Overall, GDPs overestimated the temperature when compared with the reference data series. Nevertheless, the uncertainties were more notable in the extreme temperature $\left(T_{\max }\right.$ and $\left.T_{\min }\right)$ products than in the $T_{\text {mean }}$ products. The temperature index GDPs showed similar patterns and moderate correlation with the reference data. The spatial accuracy of all the GDPs was poor in northern Punjab, where the underestimation was strongest. The underestimation of air temperature in the northern parts of the country were also reported by different studies $[88,89]$, which simulated the air temperature by using WRF model at the upper Indus Basin and Himalaya ranges, respectively. However, the prior studies reported the different ranges of temperature underestimations, which could be the outcome of different study periods, gauges, and resolution.

In conclusion, this research provides an inclusive comparison of the widely used temperature indices GDPs and enumerates the spatial and temporal inconsistencies in selected GDPs. The results and associated procedures are useful for assessing potential GDPs and for improving our 
understanding of their application over the study region. Despite finding that the CRU product performed better than other GDPs, uncertainties remain when applying GDPs over semiarid and arid regions like Punjab, as demonstrated by the ranges of RMSE and Bias. The spatial and temporal comparisons of GDPs with reference data showed large discrepancies, with temperature differences of up to $1-2^{\circ} \mathrm{C}$ between different products within the same category. These results highlight the need for a further improvement in GDPs and for better accuracy over the arid and semiarid regions. It will also be important to note the number of stations used at each grid scale by GDPs for different regions across the globe. The magnitude of Bias for the GDPs, particularly in northern Punjab, demonstrates the importance of bias corrections before using GDPs in hydroclimate studies. This evaluation of GDPs in the study area was limited to annual time scales; future studies should focus on higher temporal and spatial resolutions. Our evaluation of the different GDPs for temperature indices will be useful when assessing potential products and their weaknesses before their reliable utilization in hydrological and meteorological applications.

\section{Data Availability}

Data used in this study are available from the corresponding author upon request.

\section{Conflicts of Interest}

The authors declare no conflicts of interest.

\section{Authors' Contributions}

Xin Li and Yingying Chen supervised and designed this study. Zain Nawaz conducted the research and wrote the manuscript. Yanlong Guo and Xufeng Wang assisted in formatting and data analysis. Kun Zhang, Naima Nawaz, and Akynbekkyzy Meerzhan helped in editing the manuscript.

\section{Acknowledgments}

The authors acknowledge the financial support of the Strategic Priority Research Program of the Chinese Academy of Sciences (Grant no. XDA20100104) and the National Natural Science Foundation of China (Grant no. 41630856) for this study. The authors used in situ data from the Pakistan Meteorological Department (PMD). The authors cordially appreciate the PMD, whose efforts made it possible for them to access the data. The authors also acknowledge the support of the CAS-TWAS president fellowship program for PhD.

\section{References}

[1] Z. Nawaz, X. Li, Y. Chen, Y. Guo, X. Wang, and N. Nawaz, "Temporal and spatial characteristics of precipitation and temperature in Punjab, Pakistan," Water, vol. 11, no. 9, p. 1916, 2019.
[2] R. Huth and L. Pokorná, "Parametric versus non-parametric estimates of climatic trends," Theoretical and Applied Climatology, vol. 77, no. 1-2, pp. 107-112, 2004.

[3] S. Ragettli, W. W. Immerzeel, and F. Pellicciotti, "Contrasting climate change impact on river flows from high-altitude catchments in the Himalayan and Andes Mountains," Proceedings of the National Academy of Sciences, vol. 113, no. 33, pp. 9222-9227, 2016.

[4] A. Berardy and M. V. Chester, "Climate change vulnerability in the food, energy, and water nexus: concerns for agricultural production in Arizona and its urban export supply," Environmental Research Letters, vol. 12, no. 3, Article ID 035004, 2017.

[5] K. E. Trenberth, P. D. Jones, P. Ambenje et al., "Observations: surface and atmospheric climate change," in Climate Change 2007: The Physical Science Basis. Contribution of Working Group I to the Fourth Assessment Report of the Intergovernmental Panel on Climate Change, pp. 235-336, Cambridge University Press, New York, NY, USA, 2007.

[6] M. J. Iqbal and J. Quamar, "Measuring temperature variability of five major cities of Pakistan," Arabian Journal of Geosciences, vol. 4, no. 3-4, pp. 595-606, 2011.

[7] Y.-Y. Ren, G.-Y. Ren, X.-B. Sun et al., "Observed changes in surface air temperature and precipitation in the Hindu Kush Himalayan region over the last 100-plus years," Advances in Climate Change Research, vol. 8, no. 3, pp. 148-156, 2017.

[8] X.-B. Sun, G.-Y. Ren, A. B. Shrestha et al., "Changes in extreme temperature events over the hindu kush Himalaya during 1961-2015," Advances in Climate Change Research, vol. 8, no. 3, pp. 157-165, 2017.

[9] H. E. Beck, M. Pan, T. Roy et al., "Daily evaluation of 26 precipitation datasets using stage-IV gauge-radar data for the CONUS," Hydrology and Earth System Sciences, vol. 23, no. 1, pp. 207-224, 2019.

[10] M. Jin and R. E. Dickinson, "New observational evidence for global warming from satellite," Geophysical Research Letters, vol. 29, no. 10, pp. 31-39, 2002.

[11] S. Shahid, S. B. Harun, and A. Katimon, "Changes in diurnal temperature range in Bangladesh during the time period 1961-2008," Atmospheric Research, vol. 118, pp. 260-270, 2012.

[12] S. D. Río, M. A. Iqbal, A. Cano-Ortiz, L. Herrero, A. Hassan, and A. Penas, "Recent mean temperature trends in Pakistan and links with teleconnection patterns," International Journal of Climatology, vol. 33, no. 2, pp. 277-290, 2013.

[13] M. R. Hamdi, M. Abu-Allaban, A. Elshaieb, M. Jaber, and N. M. Momani, "Climate change in Jordan: a comprehensive examination approach," American Journal of Environmental Sciences, vol. 5, no. 1, pp. 58-68, 2009.

[14] C. Matti, A. Pauling, M. Küttel, and H. Wanner, "Winter precipitation trends for two selected European regions over the last 500 years and their possible dynamical background," Theoretical and Applied Climatology, vol. 95, no. 1-2, pp. 9-26, 2009.

[15] P. Singh, V. Kumar, T. Thomas, and M. Arora, "Basin-wide assessment of temperature trends in northwest and central India/estimation par bassin versant de tendances de température au nord-ouest et au centre de l'Inde," Hydrological Sciences Journal, vol. 53, no. 2, pp. 421-433, 2008.

[16] A. D. L. Casa and O. Nasello, "Breakpoints in annual rainfall trends in Córdoba, Argentina," Atmospheric Research, vol. 95, no. 4, pp. 419-427, 2010.

[17] S. Jiang, L. Ren, Y. Hong et al., "Comprehensive evaluation of multi-satellite precipitation products with a dense rain gauge network and optimally merging their simulated hydrological 
flows using the Bayesian model averaging method," Journal of Hydrology, vol. 452-453, pp. 213-225, 2012.

[18] X. Liu, T. Yang, K. Hsu, C. Liu, and S. Sorooshian, "Evaluating the streamflow simulation capability of PERSIANN-CDR daily rainfall products in two river basins on the Tibetan Plateau," Hydrology and Earth System Sciences, vol. 21, no. 1, pp. 169-181, 2017.

[19] W. Wang, H. Lu, T. Zhao, L. Jiang, and J. Shi, "Evaluation and comparison of daily rainfall from latest GPM and TRMM products over the Mekong River Basin," IEEE Journal of Selected Topics in Applied Earth Observations and Remote Sensing, vol. 10, no. 6, pp. 2540-2549, 2017.

[20] M. S. Nashwan, S. Shahid, E.-S. Chung, K. Ahmed, and Y. H. Song, "Development of climate-based index for hydrologic hazard susceptibility," Sustainability, vol. 10, no. 7 , p. 2182, 2018.

[21] T. P. Albright, A. M. Pidgeon, C. D. Rittenhouse et al., "Combined effects of heat waves and droughts on avian communities across the conterminous United States," Ecosphere, vol. 1, no. 5, pp. 1-22, 2010.

[22] E. Nkiaka, N. R. Nawaz, and J. C. Lovett, "Evaluating global reanalysis precipitation datasets with rain gauge measurements in the Sudano-Sahel region: case study of the Logone catchment, Lake Chad Basin," Meteorological Applications, vol. 24, no. 1, pp. 9-18, 2017.

[23] Y. Zhao, Q. Xie, Y. Lu, and B. Hu, "Hydrologic evaluation of TRMM multisatellite precipitation analysis for Nanliu river basin in Humid Southwestern China," Scientific Reports, vol. 7, no. 1, p. 2470, 2017.

[24] L. Häggmark, K.-I. Ivarsson, S. Gollvik, and P.-O. Olofsson, "Mesan, an operational mesoscale analysis system," Tellus A: Dynamic Meteorology and Oceanography, vol. 52, no. 1, pp. 2-20, 2000.

[25] K. E. Kunkel, R. S. Vose, L. E. Stevens, and R. W. Knight, "Is the monthly temperature climate of the United States becoming more extreme?" Geophysical Research Letters, vol. 42, no. 2, pp. 629-636, 2015.

[26] C. Daly, M. E. Slater, J. A. Roberti, S. H. Laseter, and L. W. Swift Jr., "High-resolution precipitation mapping in a mountainous watershed: ground truth for evaluating uncertainty in a national precipitation dataset," International Journal of Climatology, vol. 37, pp. 124-137, 2017.

[27] I. Khairul, N. Mastrantonas, M. Rasmy, T. Koike, and K. Takeuchi, "Inter-comparison of gauge-corrected global satellite rainfall estimates and their applicability for effective water resource management in a transboundary river basin: the case of the Meghna River basin," Remote Sensing, vol. 10, no. 6, p. 828, 2018.

[28] S. Samadi, G. J. Carbone, M. Mahdavi, F. Sharifi, and M. R. Bihamta, "Statistical downscaling of climate data to estimate streamflow in a semi-arid catchment," Hydrology and Earth System Sciences Discussions, vol. 9, no. 4, pp. 4869-4918, 2012.

[29] W. Buytaert, J. Friesen, J. Liebe, and R. Ludwig, “Assessment and management of water resources in developing, semi-arid and arid regions," Water Resources Management, vol. 26, no. 4, pp. 841-844, 2012.

[30] W. Ahmad, A. Fatima, U. K. Awan, and A. Anwar, "Analysis of long term meteorological trends in the middle and lower Indus Basin of Pakistan-a non-parametric statistical approach," Global and Planetary Change, vol. 122, pp. 282-291, 2014.

[31] N. Khan, S. Shahid, T. B. Ismail, and X.-J. Wang, "Spatial distribution of unidirectional trends in temperature and temperature extremes in Pakistan," Theoretical and Applied Climatology, vol. 136, no. 3-4, pp. 899-913, 2018.

[32] K. Ahmed, S. Shahid, X. Wang, N. Nawaz, and K. Najeebullah, "Evaluation of gridded precipitation datasets over arid regions of Pakistan," Water, vol. 11, no. 2, p. 210, 2019.

[33] S. Khattak, N. U. Reman, M. Sharif, and M. A. Khan, "Analysis of streamflow data for trend detection on major rivers of the Indus Basin," Journal of Himalayan Earth Sciences, vol. 48, no. 1, pp. 99-111, 2015.

[34] M. Tan and Z. Duan, "Assessment of GPM and TRMM precipitation products over Singapore," Remote Sensing, vol. 9, no. 7, p. 720, 2017.

[35] M. W. Ashiq, C. Zhao, J. Ni, and M. Akhtar, "GIS-based highresolution spatial interpolation of precipitation in mountain-plain areas of upper Pakistan for regional climate change impact studies," Theoretical and Applied Climatology, vol. 99, no. 3-4, pp. 239-253, 2010.

[36] F. Abbas, "Analysis of a historical (1981-2010) temperature record of the Punjab province of Pakistan," Earth Interactions, vol. 17, no. 15, pp. 1-23, 2013.

[37] S. U. Khan, M. U. Hasan, F. K. Khan, and A. Bari, "Climate classification of Pakistan," in Proceedings of the Balwois Conference: Republic of Macedonia, pp. 1-47, Skopje, Macedonia, 2010.

[38] U. Asmat, H. Athar, A. Nabeel, and M. Latif, "An AOGCM based assessment of interseasonal variability in Pakistan," Climate Dynamics, vol. 50, no. 1-2, pp. 349-373, 2018.

[39] M. Iqbal, J. Wen, X. Wang et al., "Assessment of air temperature trends in the source region of yellow river and its sub-basins, China," Asia-Pacific Journal of Atmospheric Sciences, vol. 54, no. 1, pp. 111-123, 2018.

[40] J. M. Mitchell, B. Dzerdzeevskii, H. Flohn et al., "Climatic change: report of a working group of the commission for climatology," Technical Note, No. 79, World Meteorological Organization, Geneva, Switzerland, 1966.

[41] T. C. Peterson, D. R. Easterling, T. R. Karl et al., "Homogeneity adjustments of in situ atmospheric climate data: a review," International Journal of Climatology, vol. 18, no. 13, pp. 1493-1517, 1998.

[42] M. A. Kohler, "On the use of double-mass analysis for testing the consistency of meteorological records and for making required adjustments," Bulletin of the American Meteorological Society, vol. 30, no. 5, pp. 188-195, 1949.

[43] H. Tabari, B. S. Somee, and M. R. Zadeh, "Testing for longterm trends in climatic variables in Iran," Atmospheric Research, vol. 100, no. 1, pp. 132-140, 2011.

[44] T. A. Buishand, "Some methods for testing the homogeneity of rainfall records," Journal of Hydrology, vol. 58, no. 1-2, pp. 11-27, 1982.

[45] P. Craven and G. Wahba, "Smoothing noisy data with spline functions," Numerische Mathematik, vol. 31, no. 4, pp. 377403, 1978.

[46] M. F. Hutchinson and P. E. Gessler, "Splines-more than just a smooth interpolator," Geoderma, vol. 62, no. 1-3, pp. 45-67, 1994.

[47] T. Partal, "Wavelet transform-based analysis of periodicities and trends of Sakarya basin (Turkey) streamflow data," River Research and Applications, vol. 26, no. 6, pp. 695-711, 2010.

[48] P. Sonali and D. N. Kumar, "Review of trend detection methods and their application to detect temperature changes in India," Journal of Hydrology, vol. 476, pp. 212-227, 2013.

[49] M. Sayemuzzaman and M. K. Jha, "Seasonal and annual precipitation time series trend analysis in North Carolina, 
United States," Atmospheric Research, vol. 137, pp. 183-194, 2014.

[50] I. Harris, P. D. Jones, T. J. Osborn, and D. H. Lister, "Updated high-resolution grids of monthly climatic observations-the CRU TS3.10 Dataset," International Journal of Climatology, vol. 34, no. 3, pp. 623-642, 2014.

[51] C. J. Willmott and K. Matsuura, "Smart interpolation of annually averaged air temperature in the United States," Journal of Applied Meteorology, vol. 34, no. 12, pp. 2577-2586, 1995.

[52] P. Xie, M. Chen, and W. Shi, "CPC unified gauge-based analysis of global daily precipitation," in Proceedings of the Preprints, 24th Conference on Hydrology, American Meteor Society, Atlanta, GA, USA, 2010.

[53] A. Yatagai, K. Kamiguchi, O. Arakawa, A. Hamada, N. Yasutomi, and A. Kitoh, "APHRODITE: constructing a long-term daily gridded precipitation dataset for Asia based on a dense network of rain gauges," Bulletin of the American Meteorological Society, vol. 93, no. 9, pp. 1401-1415, 2012.

[54] J. H. Lawrimore, M. J. Menne, B. E. Gleason et al., "An overview of the global historical climatology network monthly mean temperature data set, version 3," Journal of Geophysical Research, vol. 116, no. D19, 2011.

[55] J. Sheffield, G. Goteti, and E. F. Wood, "Development of a 50year high-resolution global dataset of meteorological forcings for land surface modeling," Journal of Climate, vol. 19, no. 13, pp. 3088-3111, 2006.

[56] K. E. Taylor, "Summarizing multiple aspects of model performance in a single diagram," Journal of Geophysical Research: Atmospheres, vol. 106, no. D7, pp. 7183-7192, 2001.

[57] T. Condom, P. Rau, and J. C. Espinoza, "Correction of TRMM 3B43 monthly precipitation data over the mountainous areas of peru during the period 1998-2007," Hydrological Processes, vol. 25, no. 12, pp. 1924-1933, 2011.

[58] Y. Yang and Y. Luo, "Evaluating the performance of remote sensing precipitation products CMORPH, PERSIANN, and TMPA, in the arid region of northwest China," Theoretical and Applied Climatology, vol. 118, no. 3, pp. 429-445, 2014.

[59] Y. Chen, Y. Guan, G. Shao, and D. Zhang, "Investigating trends in streamflow and precipitation in Huangfuchuan Basin with wavelet analysis and the Mann-Kendall test," Water, vol. 8, no. 3, p. 77, 2016.

[60] P. Yang, J. Xia, Y. Zhang, and S. Hong, "Temporal and spatial variations of precipitation in Northwest China during 1960-2013," Atmospheric Research, vol. 183, pp. 283-295, 2017.

[61] Y. Hu, S. Maskey, S. Uhlenbrook, and H. Zhao, "Streamflow trends and climate linkages in the source region of the Yellow River, China," Hydrological Processes, vol. 25, no. 22, pp. 3399-3411, 2011.

[62] I. Ahmad, D. Tang, T. Wang, M. Wang, and B. Wagan, "Precipitation trends over time using Mann-Kendall and spearman's rho tests in swat river basin, Pakistan," Advances in Meteorology, vol. 2015, Article ID 431860, 15 pages, 2015.

[63] P. K. Sen, "Estimates of the regression coefficient based on Kendall's tau," Journal of the American Statistical Association, vol. 63, no. 324, pp. 1379-1389, 1968.

[64] K. E. Kunkel, K. Andsager, and D. R. Easterling, "Long-term trends in extreme precipitation events over the conterminous United States and Canada," Journal of Climate, vol. 12, no. 8, pp. 2515-2527, 1999.

[65] X. Zhang, F. W. Zwiers, and G. Li, "Monte Carlo experiments on the detection of trends in extreme values," Journal of Climate, vol. 17, no. 10, pp. 1945-1952, 2004.
[66] M. Zarenistanak, A. G. Dhorde, and R. H. Kripalani, “Trend analysis and change point detection of annual and seasonal precipitation and temperature series over southwest Iran," Journal of Earth System Science, vol. 123, no. 2, pp. 281-295, 2014.

[67] Z. Hussain, F. Ludwig, E. Moors, B. Ahmad, A. Khan, and P. Kabat, "Science of the total environment an appraisal of precipitation distribution in the high-altitude catchments of the Indus basin," Science of the Total Environment, vol. 548-549, pp. 289-306, 2016.

[68] M. Türkeş and U. M. Sümer, "Spatial and temporal patterns of trends and variability in diurnal temperature ranges of Turkey," Theoretical and Applied Climatology, vol. 77, no. 3-4, pp. 195-227, 2004.

[69] M. Xu, S. Kang, H. Wu, and X. Yuan, "Detection of spatiotemporal variability of air temperature and precipitation based on long-term meteorological station observations over Tianshan Mountains, Central Asia," Atmospheric Research, vol. 203, pp. 141-163, 2018.

[70] M. M. Rashid, S. Beecham, and R. K. Chowdhury, "Assessment of trends in point rainfall using continuous wavelet transforms," Advances in Water Resource, vol. 82, pp. 1-15, 2015.

[71] M. Shafiq and M. A. Kakar, "Effects of drought on livestock sector in Balochistan Province of Pakistan," International Journal of Agriculture \& Biology, vol. 9, no. 4, 2007.

[72] H. Xie, C. Ringler, T. Zhu, and A. Waqas, "Droughts in Pakistan: a spatiotemporal variability analysis using the Standardized Precipitation Index," Water International, vol. 38, no. 5, pp. 620-631, 2013.

[73] F. J. Tapiador, F. J. Turk, W. Petersen et al., "Global precipitation measurement: methods, datasets and applications," Atmospheric Research, vol. 104-105, pp. 70-97, 2012.

[74] M. S. Nashwan and S. Shahid, "Symmetrical uncertainty and random forest for the evaluation of gridded precipitation and temperature data," Atmospheric Research, vol. 230, Article ID 104632, 2019.

[75] M. Rapaić, R. Brown, M. Markovic, and D. Chaumont, “An evaluation of temperature and precipitation surface-based and reanalysis datasets for the canadian arctic, 1950-2010," Atmosphere-Ocean, vol. 53, no. 3, pp. 283-303, 2015.

[76] J. O. Tostes, G. B. Lyra, J. F. Oliveira- Júnior, and M. R. Francelino, "Assessment of gridded precipitation and air temperature products for the state of acre, southwestern Amazonia, Brazil," Environmental Earth Sciences, vol. 76, no. 4, 2017.

[77] A. Bandyopadhyay, G. Nengzouzam, W. R. Singh, N. Hangsing, and A. Bhadra, "Comparison of various reanalyses gridded data with observed data from meteorological stations over India," in Proceedings of the 13th International Conference on Hydroinformatics 2018 (HIC 2018), vol. 3, pp. 190-180, Palermo, Italy, 2018.

[78] M. Tanarhte, P. Hadjinicolaou, and J. Lelieveld, "Intercomparison of temperature and precipitation data sets based on observations in the Mediterranean and the Middle East," Journal of Geophysical Research: Atmospheres, vol. 117, no. D12, 2012.

[79] S. S. Roy, M. S. K. Kiany, and R. C. Balling, "A significant population signal in Iranian temperature records," International Journal of Atmospheric Sciences, vol. 2016, Article ID 1603693, 7 pages, 2016.

[80] A. Farhat, A. Ahmad, M. Safeeq et al., "Changes in precipitation extremes over arid to semiarid and subhumid Punjab, Pakistan," Theoretical and Applied Climatology, vol. 116, no. 3-4, pp. 671-680, 2013. 
[81] S. U. Islam, N. Rehman, and M. M. Sheikh, "Future change in the frequency of warm and cold spells over Pakistan simulated by the PRECIS regional climate model," Climatic Change, vol. 94, no. 1-2, pp. 35-45, 2009.

[82] G. Rahman, Atta-Ur-Rahman, Samiullah, and M. Dawood, "Spatial and temporal variation of rainfall and drought in Khyber Pakhtunkhwa Province of Pakistan during 1971-2015," Arabian Journal of Geosciences, vol. 11, no. 3, p. 46, 2018.

[83] Bharti V., Singh C., Journal of Geophysical Research: Atmospheres, 458-473, 2015.

[84] G. Ren and Y. Zhou, "Urbanization effect on trends of extreme temperature indices of national stations over Mainland China, 1961-2008," Journal of Climate, vol. 27, no. 6, pp. 2340-2360, 2014.

[85] Article R., Reviews of Geophysics, 79-107, 2017.

[86] M. New, D. Lister, M. Hulme, and I. Makin, "A high-resolution data set of surface climate over global land areas," Climate Research, vol. 21, pp. 1-25, 2002.

[87] D. J. McEvoy, J. F. Mejia, and J. L. Huntington, "Use of an observation network in the great basin to evaluate gridded climate data," Journal of Hydrometeorology, vol. 15, no. 5, pp. 1913-1931, 2014.

[88] J. Norris, L. M. V. Carvalho, C. Jones, and F. Cannon, "Deciphering the contrasting climatic trends between the central Himalaya and Karakoram with 36 years of WRF simulations," Climate Dynamics, vol. 52, no. 1-2, pp. 159-180, 2019.

[89] G. H. Dars, C. Strong, A. K. Kochanski, K. Ansari, and S. H. Ali, "Applied sciences the spatiotemporal variability of temperature and precipitation over the upper indus basin : an evaluation of 15 year WRF simulations," Applied Sciences, vol. 10, no. 5, p. 1765, 2020. 